OPEN ACCESS

Edited by:

Muhammad Asif,

University of Limerick, Ireland

Reviewed by:

Gang Zhao

University of Jinan, China

Xing-Long Wu,

Northeast Normal University, China

Liang Zhou,

Wuhan University of

Technology, China

*Correspondence:

Mudassir laba

mudassir.iqbal@sns.nust.edu.pk

Specialty section:

This article was submitted to

Energy Materials,

a section of the journa

Frontiers in Materials

Received: 15 March 2020

Accepted: 18 May 2020

Published: 17 July 2020

Citation:

Ashraf I, Rizwan S and lqbal M (2020) A Comprehensive Review on the

Synthesis and Energy Applications of

Nano-structured Metal Nitrides.

Front. Mater. 7:181

doi: 10.3389/fmats.2020.00181

\section{A Comprehensive Review on the Synthesis and Energy Applications of Nano-structured Metal Nitrides}

\author{
Iffat Ashraf ${ }^{1}$, Syed Rizwan ${ }^{2}$ and Mudassir Iqbal ${ }^{1 *}$ \\ ${ }^{1}$ Department of Chemistry, School of Natural Sciences, National University of Sciences and Technology (NUST), Islamabad, \\ Pakistan, ${ }^{2}$ Physics Characterization and Simulations Lab (PCSL), Department of Physics, School of Natural Sciences (SNS), \\ National University of Sciences and Technology (NUST), Islamabad, Pakistan
}

Nanosized metal nitrides, due to their chemical characteristics which make them sustainable alternatives to noble metals in catalysis, have drawn the attention of researchers worldwide. Transition metal nitrides are very similar in their method of synthesis, properties, and applications. Their synthetic parameters are considered to be the main factor for determining the effectiveness of metal nitrides in photocatalysis, energy storage devices, remediation of environmental pollutants, gas sensors, and biomedical applications. This review focuses on very recent advances made in synthetic approaches and electrocatalytic applications of metal nitrides. The synthetic approaches will provide an overview of cost of production and consumption of energy and time required for synthesis. Furthermore, some recent techniques that offer new paths for researchers, such as electrochemical, sol-gel, solvothermal, sonochemical, solid-state reaction, chemical synthesis, and many more, are also discussed. Various applications in electrocatalysis, water splitting, lithium ion batteries, and super-capacitors, etc. are summarized. We are confident that this review will provide very useful information for the upcoming community of researchers interested in synthesizing nitrides for various applications.

Keywords: metal nitrides, properties, synthesis, water splitting, LIBs, SCs, NIBs, fuel cells

\section{INTRODUCTION}

Nanostructured materials have been shown greater attention because of their excellent properties in many fields, for example nanomagnetism, electrocatalysis, environmental, and biomedical applications. Development in nanotechnology is helpful to enhance properties related to their size, which has proven to be an important factor.

Nitrogen is considered to be a versatile element that has the ability to form compounds with many elements of the periodic table, especially metals. The bond formation of nitrogen with the least electronegative elements, such as transition elements, forms very stable compounds in the form of metal nitrides. Metal nitrides have richer bonding schemes (Hugosson et al., 2004; Yang Z. et al., 2017), owing to the greater electrons present in the bond than that of electrons localized on the anion lattice that is visualized in their optical and electronic properties. Nitrides are compounds in which $\mathrm{N}$ is formally anionic $\mathrm{N}^{3-}$.

Metal-nitrogen bonds are rich in electrons in relation to chemical bonding, hence making nitrides essentially more interesting because of their electronic, catalytic, and magnetic properties 
(Giordano and Antonietti, 2011). Nitrides can be classified according to their bonding: (i) Nitrides that are formed from metals of group I and group II generate compounds that have an ionic bond. For instance, $\mathrm{Li}_{3} \mathrm{~N}$ shows excellent ionic conductivity (Alpen et al., 1977); (ii) Members of group III and group IV form nitrides that have a covalent bond. They are seen to be semi-conductive or non-conductive with hardness and a higher melting point (Wild et al., 1972); and (iii) Transition metal nitride bonding takes place with contributions from ionic, covalent, and metallic bonding, that for are essential for their versatile physical and chemical properties (Didziulis et al., 2003; Hugosson et al., 2004).

Nitrides are considered to be more covalent as compared to other oxides because of their lower $2 p$ orbital of Oxygen as compared to that of Nitrogen. Because of the greater covalent character of nitrides, they have many photo-electric applications, for instance LEDs (light-emitting diodes) (Nakamura, 2015), laser diodes, wide band gap power electronics, etc.

The formation of transition metal nitrides alters the d-band of the parent metal that results in the decrease of the d-band metal. This decrease of the d-band metal causes increased DOS (density of states) near Fermi level compared to that of the parent metal (Siegel, 1979). These DOS changes in transition metal nitrides promotes catalytic activities, that are unlike those from the parent metals and are instead similar to noble metals (Jansen and Hoffmann, 1988; Oyama, 1992).

The use of nitrides is increasing rapidly as they have the ability to replace standard goods for wider applications, such as electrical devices, gas sensing, ceramics, environmental remediation, and medicines. Recently, nanoparticles that have different morphologies and hollow structures have been attracting the attention of researchers, owing to their low density, large surface area, thin walls, ionic conductivity, electrical properties, enhanced chemical activity, and high conductivity (Cheng et al., 2006; Guo et al., 2008; Zhao et al., 2008; Karan et al., 2009; Yu et al., 2009; Sinev et al., 2018; Cao et al., 2020). Metal nitrides also possess superior properties such as being weather resistant, higher melting points, enhanced electronic properties, and electrocatalytic properties (Rohmer et al., 2000; Chang et al., 2002; Nelson and Wagner, 2002) when compared to pristine metal oxide. Because of a stronger covalent bond, these materials have a higher mechanical strength and wear resistance. They can be used for semiconductor devices (GaN, AlN, InN), for hydrogen storage (Luo et al., 2009), as a magnetic material (Hadjipanayis et al., 1992; Hadjipanayis, 1999), gas barrier (Oyama, 1996), and also as metal oxy-nitrides (Alexander and Hargreaves, 2010; Chen et al., 2010). Transition metal nitrides are considered to be promising electrode materials for many devices, such as supercapacitors, due to their physical, chemical, and mechanical properties (Arico et al., 2011; Chen et al., 2012). Transition metal nitrides such as $\mathrm{Mo}_{\mathbf{x}} \mathrm{N}$ (Shah et al., 2014), VN (Eustache et al., 2013; Lucio-Porto et al., 2014), CrN (Banakh et al., 2003), TiN (Achour et al., 2015; Kao et al., 2016), $\mathrm{Ni}_{3} \mathrm{~N}$ (Balogun et al., 2016), and $\mathrm{Mo}_{2} \mathrm{~N}(\mathrm{He}$ et al., 2020) are considered to be potent electrode materials for super capacitors because of their low cost, excellent electronic conductivity, high stability at higher temperatures, and good chemical resistance. 2D (two-dimensional) materials, having versatile electrical and electronic properties, has been gaining increased research attention due to their being seen as different from their bulk counterparts.

MXenes, a type of 2D metal carbide, and nitrides are in greater demand because of their outstanding properties and applications. Their properties, including greater electrical conductivity and their hydrophilic surfaces (Ghidiu et al., 2014; Anasori et al., 2017), have made them potent candidates for use in energy storing devices (Lukatskaya et al., 2013; Naguib et al., 2013; Zhao et al., 2015), EMI (electromagnetic interference) shielding (Shahzad et al., 2016; Liu J. et al., 2017), and many more applications.

MXenes can be used in transparent conductors (Wu and Yang, 2017), field effect transistors (Kim et al., 2015), super capacitors (Khazaei et al., 2016), LIBs (Li-ion batteries), magnetic interface (MI) shielding (Shahzad et al., 2016), as fillers in polymeric hybrid nanocomposites (Wang P. et al., 2017), purifiers (Roy et al., 2015), appropriate reactant for dyes, catalysts (Wang L. et al., 2017) used in methane storage, as photo catalysts for $\mathrm{H}_{2}$ production (Ran et al., 2017), and also as a ceramic biomaterial with increased photo thermal conversion efficiency for the treatment of cancer. In theoretical terms, MXenes have shown many possible applications in magnetic, electronic, optical, thermoelectronic (Gandi et al., 2016), and sensing devices (He et al., 2015), as well as being a new material for nano scale superconductivity.

The use of nitride MXenes in energy storage devices and plasmonics (Naik et al., 2012; Soundiraraju and George, 2017) has been gaining greater attention (Morel et al., 2016) due to their higher electrical conductance as compared to that of metal carbides could be used. For instance, the higher volumetric capacitance of $928 \mathrm{Fcm}^{-3}$ in $\mathrm{H}_{2} \mathrm{SO}_{4}$ electrolyte shows an outstanding rate performance in the case of $2 \mathrm{D} \mathrm{MoN}$ (Xie et al., 2014). 2D metal nitrides are found to be interesting candidates for optics, plasmonics, metamaterial devices, and capacitors. MXenes have a larger surface area that is inherited from their $2 \mathrm{D}$ structure and shows their greater potential for electrochemical energy storing applications. Studies revealed that MXenes' surface is negatively charged because of electronegative oxygen or fluorine atoms attached in terminal groups. This is why MXene have the ability to show reversible electrochemical intercalation of cations, which includes $\mathrm{Na}^{+}$(sodium ion), as well as $\mathrm{Mg}^{+2}$ (magnesium) and $\mathrm{Al}^{+3}$ (aluminum) ions, that have stronger Columbic interactions between cations and MXenes. An overview of structure, synthetic methodologies, and various applications of metal nitrides are discussed in this article.

\section{Synthesis of Metal Nitrides}

Nitrides are comprised of a huge class of compounds that have a larger structural variety and a greater range of fields in which they could be applied. Common synthesis routes include carbothermal reduction, solid state metathesis, and high temperature approaches, such as direct nitridation.

There are two synthetic methods for the formation of metal nitrides: (i) the physical method and (ii) the chemical method (Giordano and Antonietti, 2011). The physical method includes 
physical vapor deposition (Andrievski, 1997), plasma, and laser methods (Vissokov et al., 2003; Schaaf et al., 2005). These methods are used for the synthesis of a few products, such as TiN and CrN. Whereas the chemical method involves reactions of metals with nitrogen $\left(\mathrm{N}_{2}\right)$ sources $\left(\mathrm{NH}_{3}\right.$ or $\mathrm{N}_{2}$ gas) at increased temperatures $\left(800-2,000^{\circ} \mathrm{C}\right.$ ) (Volpe and Boudart, 1985; Buha et al., 2007; Yao et al., 2009). Chemical methods are considered to be more flexible with a wide range of nitrides.

Some synthetic methods are discussed here.

\section{Solvothermal Method}

The solvothermal method is very similar to the hydrothermal method. In solvothermal method, precursor solvent is nonaqueous while in hydrothermal method solvent used is aqueous. This method is helpful to control the size, shape, and crystallinity of nanosized metal oxides. These parameters can be altered by reaction time, solvent type, temperature, etc. By using this method of synthesis, products of a metastable state and specific phases can be obtained, and materials that have a high vapor pressure and low melting points can be easily synthesized. The main disadvantage of this technique is that it requires a longer time, which may cause the agglomeration of nanoparticles. Moreover, the high pressure developed in the autoclave may cause an explosion.

Balogun et al. (2014) synthesized TiN nanowires by annealing on a fabric of carbon. Synthesized nanoparticles were confirmed by SEM (scanning electron microscopy), TEM (transmission electron microscopy), HRTEM (high resolution TEM), XRD (Xray diffraction), and SAED (selected area electron diffraction) techniques (Balogun et al., 2014).

Wang G. et al. (2017) synthesized VN nanoribbons aerogels with a three-dimensional structure. This process was developed through the formation of ammonia nitridation and vanadium oxides using the hydrothermal method. In this method of synthesis, a mixture of $\mathrm{NH}_{4} \mathrm{VO}_{3}$ in water and ethanol containing a few drops of $\mathrm{HCl}$ was transferred to a Teflon-lined steel autoclave for $20 \mathrm{~h}$ at $180^{\circ} \mathrm{C}$. After the process of washing and drying, the obtained product was annealed at $550^{\circ} \mathrm{C}$ for $3 \mathrm{~h}$ under a mixture of $\mathrm{NH}_{3}$ and $\mathrm{Ar}$ gases. Results showed that the as-synthesized sample contained organized microstructures, and hence had the ability to provide multi-pathways for the transfer of electrons.

Recently, Jia et al. (2020) developed a strategy to form a $3 \mathrm{D}$ structure of $\mathrm{VN}$ microsheets shelled with $\mathrm{N}$-doped carbon layer (VN@NC) for its electrochemical uses by using PVP as a carbon source and melamine as a nitrogen source. VN@NC was synthesized using the hydrothermal method, in which a $3 \mathrm{D}$ sponge-like $\mathrm{V}_{2} \mathrm{O}_{5}$ aerogel was synthesized using the hydrothermal treatment with $\mathrm{H}_{2} \mathrm{O}_{2}$ and then was freeze dried. Through the melamine reduction process, $\mathrm{V}_{2} \mathrm{O}_{5}$ was converted into porous crystalline $\mathrm{VN}$ and an $\mathrm{N}$ doped carbon layer was prepared by pyrolysis of PVP.

A 3D hollow structure has been an effective strategy for improving structural stability and capacity performance. In this respect, Wang et al. (2019) synthesized MoN-nitrogen doped carbon (MoN@NC) hollow spheres assembled from nanosheets by the one-pot hydrothermal process followed by the in-situ nitridation process. $\mathrm{MoO}_{2}(\mathrm{acac})_{2}$, glucose, and thiourea were used as precursors for the synthesis of MoN@NC. All of these were dissolved in deionized water and stirred for $30 \mathrm{~min}$, then transferred to a Teflon-lined steel autoclave at $200^{\circ} \mathrm{C}$ for $12 \mathrm{~h}$ in an oven. After washing and drying, the resulting product was transferred to a horizontal tube furnace and annealed at $800^{\circ} \mathrm{C}$ for $1.5 \mathrm{~h}$ in the presence of ammonia to obtain MoN@NC hollow spheres. The morphology and internal structure of this as-synthesized hollow sphere was measured by XRD, XPS (X-ray photoelectron spectroscopy), SEM, and TEM.

It may be noted that this method of synthesis can be easily rendered for a wide range of compositions and is considered to be a convenient method for the synthesis of all types of nitrides.

\section{Sol Gel Method}

In this method of synthesis, metal solutions are required for the synthesis of solid materials, passing through a gel intermediate containing both solid and liquid phases. This method requires low temperature synthesis as compared to other method of synthesis with fast rates of reaction and greater surface areas. This method is a bit complex to ensure good control over various parameters of synthesis such as $\mathrm{pH}$, temperature, reactivity of metal alkoxide toward hydrolysis, alkoxy functional group steric hindrance, etc. In ceramic synthesis, starting materials that have a high melting point are difficult to handle. After successful preparation in metal oxides, this method allowed researchers to set trends for the synthesis of metal nitrides.

Zhang et al. (2015) reported the synthesis of $\mathrm{Fe}_{3} \mathrm{~N}$ by using a novel precursor that was synthesized through the coordination of ferric chloride and triethylamine. With a continuous flow of nitrogen, calcination of the as-synthesized precursor was carried out at different temperatures for $30 \mathrm{~min}$ at a $20^{\circ} \mathrm{C} / \mathrm{min}$ heating rate. In this case, investigation of hydrazine decomposition and magnetic properties were carried out.

Furthermore, in 2019 Yazdan et al. (2019) synthesized an agarose hydrogel based composite with different boron nitride $(\mathrm{BN})$ fillers through which thermal conductivities were investigated for the very first time. BN shows excellent chemical stability, along with thermal stability and mechanical strength. Hydrogel was synthesized by mixing agarose powder with deionized water at $100^{\circ} \mathrm{C}$ for $1 \mathrm{~h}$. The solution was placed on a glass plate. $\mathrm{BN} /$ hydrogel was synthesized by mixing $\mathrm{BN}$ powder with deionized water and was stirred for $30 \mathrm{~min}$. Agarose powder was then mixed in the solution. This solution was heated for $1 \mathrm{~h}$ at $100^{\circ} \mathrm{C}$ and then placed on a glass plate for the formation of the $\mathrm{BN} /$ hydrogel composite. The $\mathrm{BN}$ content in the composite varied $(3,5,10$, and $15 \mathrm{wt} \%)$.

Zhang Y. et al. (2016) synthesized cobalt nitride nanowires through the conversion of a cobalt oxide precursor by the treatment of nitrogen $\left(\mathrm{N}_{2}\right)$ radio frequency plasma. This synthesis is more favorable as it requires a shorter reaction time (about $1 \mathrm{~min}$ ) at room temperature as compared to conventional high temperature ammonia annealing that requires a higher temperature. Confirmation of nanoparticles was carried out by XRD, XPS, SEM, TEM, and electrochemical impedance spectroscopy (EIS) techniques.

Moreover, Schnepp et al. (2011) synthesized sponge-like $\mathrm{Fe}_{3} \mathrm{~N}$ nanostructures via the sol-gel method by utilizing 
aqueous precursors to synthesize self-expanding polypeptide foam. This method utilizes in-situ nitridation and avoids ammonolysis at increased temperatures through the controlled nucleation growth of $\mathrm{Fe}_{3} \mathrm{O}_{4}$ nanoparticles that has an optimized growth process.

This method of synthesis can be used with many metals for the synthesis of highly crystalline nanoparticles of corresponding nitrides. Furthermore, the addition of fibers or polymer beads can be helpful in the synthesis of various sizes of metal nitrides and can ensure no agglomeration of particles occurs.

\section{Solid State Synthesis}

In this method of synthesis, materials are synthesized at high temperatures. In this method, starting materials are grinded to powders in a ball mill or pestle mortar to increase the surface area. The material is pelletized after compressing by applying pressure and load in an aluminum boat. The boat is then placed in a furnace, and heating conditions are adjusted depending on the nature of the starting material. This method is not appropriate for low temperature synthesis, and the incorporation of volatile species is also difficult. Furthermore, high oxidation states are mostly unstable at high temperatures due to the release of oxygen that favors a forward reaction.

It was reported by Cui et al. (2014) that a mesoporous $\mathrm{Ti}_{0.5} \mathrm{Cr}_{0.5} \mathrm{~N}$ can be synthesized by metal oxides (ZnMO, M $=\mathrm{Cr}, \mathrm{Ti}$ ) in a solid state. In this method, $\mathrm{Cr}_{2} \mathrm{O}_{3}, \mathrm{ZnO}$, and $\mathrm{TiO}_{2}$ reacted in a temperature range of $600-1,350^{\circ} \mathrm{C}$. At least one half gram of zinc metal oxide was poured in an aluminum boat, then the ammonolysis reaction was carried out at $800^{\circ} \mathrm{C}$ ammonolysis reaction with a $150^{\circ} \mathrm{C} / \mathrm{h}$ heating rate. The as-synthesized $\mathrm{Ti}_{0}{ }_{5} \mathrm{Cr}_{0.5} \mathrm{~N}$ exhibits a highly porous, sintered structure, with a crystallite size of $20-40 \mathrm{~nm}$ which results in a high specific surface area. This method of synthesis can also be applied for the rational design of many other porous and chemically-stable materials for many technologies.

In 2016, Balamurugan et al. (2016b) developed a strategy for the synthesis of $\mathrm{FeN} /$ carbon core/shell nanoparticles embedded on nitrogen-doped graphene for high performance dye-sensitized solar cells. Several reports have shown that FeN has superior properties, such as good physical and chemical stability, a high electrical conductivity, etc. (Balogun et al., 2015; Zhu et al., 2015). In this method of synthesis, the nitrogen source used was cyanamide and through thermal annealing the desired final composites were obtained in an argon atmosphere. The structural details of the as-synthesized nanohybrid was investigated using SEM, TEM, XRD, and EDS. Results showed that Nitrogen doped graphene shells were seamlessly wrapped around iron nitride particles, which proves a strong interaction between the core and the shell.

Jin T. et al. (2018) designed a method to prepare high entropy transition metal nitrides in which transition metal chlorides $\left(\mathrm{VCl}_{3}, \mathrm{CrCl}_{3}, \mathrm{NbCl}_{5}, \mathrm{MoCl}_{5}\right.$, and $\mathrm{ZrCl}_{4}$ ) and urea formed a metal urea gel by ball-milling. A mechanochemical synthesis that was followed by a soft urea strategy was used to prepare the new class of HEMNs (high-entropy metal nitrides). Here, five different transition metal chlorides ( $\mathrm{MClx}, \mathrm{M}=\mathrm{V}, \mathrm{Cr}, \mathrm{Nb}, \mathrm{Mo}$, and $\mathrm{Zr}$ ) were mixed with urea by ball-milling in order to form a highly discrete precursor, and nitrogen gas was used for pyrolysis. It was seen that the configurational entropy was increased by using five metal elements. XRD, SEM, and HRTEM were used for confirmation. This work not only provides a new methodology for the synthesis of metal nitrides, but it is also proves helpful as it gives useful information about high-entropy materials. The following Figure 1 shows the synthetic strategy for high entropy metal nitrides.

Shi et al. (2008) reported the synthesis of mesoporous metal nitrides with the ammonia nitridation process using gassolid reactions. For this purpose, $\mathrm{CoN}$ nanowire arrays were synthesized using mesoporous cobalt oxides that are used in conjunction with ammonia gas. In this method, mesoporous silica SBA-15 was used to replicate the starting material and even at high temperatures the regularity of the structure was maintained. Using this method of synthesis, highly ordered mesoporous cobalt nitride is obtained through the conversion of $\mathrm{Co}_{3} \mathrm{O}_{4}$ nanowire replica in an ammonia atmosphere without losing the regularity of the mesostructure.

\section{High Pressure Temperature Method}

The high pressure temperature method of synthesis can be used for the synthesis of new phases of nitrides. The devices

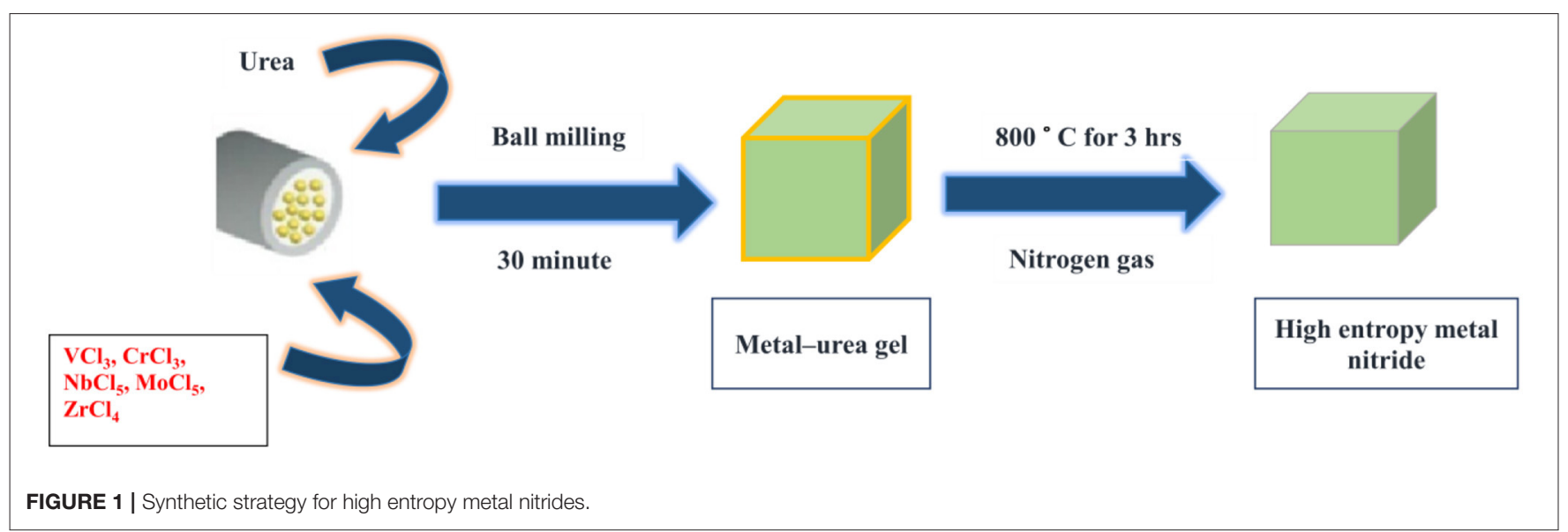


used for nitride synthesis under high pressure are the multi anvil device, diamond anvil device, autoclave, and shock wave apparatus. Reaction vessels used may be dynamic or static. High temperatures and pressure are applied by discharge of electric or magnetic energy in a reaction chamber in a dynamic system. This method is used to produce a greater amount of the sample. Temperature and pressure are applied slowly in the static system. Pressure that is released during the cooling system operates slowly. This method is helpful in the synthesis of new nitride phases, and also synthesizes high purity direct nitride products. This method requires single step enabling structural changes for the modification of electrical and magnetic properties, however, it requires significant infrastructural and operational costs as well.

Similarly, El Himri et al. (2015) reported the synthesis of $\mathrm{Nb}_{1-\mathrm{x}} \mathrm{Mo}_{\mathrm{x}} \mathrm{N}_{\mathrm{y}}$ series where, $\mathrm{x}=0.0,0.2,0.4,0.5,0.6,0.8$, 1.0. Niobium and molybdenum based ternary metal nitrides were synthesized by using $\mathrm{NbCl}_{5}$ and $\mathrm{MoCl}_{5}$. Grinding of $\mathrm{NbCl}_{5}$ and $\mathrm{MoCl}_{5}$ was carried out and then these were weighed under Ar in a glove box. The solids that were formed were then hot-pressed in hexagonal-Boron Nitride capsules. All of the synthesized compounds possessed a rock salt crystal structure with a metal atom in a face-centered cubic arrangement with nitrogen atoms occupying octahedral interstitial positions. The synthesized material has a diameter of $\sim 20 \mathrm{~nm}$, which showed that the material has a large surface area.

Wang S. et al. (2017) synthesized $\delta$-MoN with a controllable grain size using the high pressure method of synthesis. By this method of synthesis, onion-like nanocrystals were synthesized in which each layer was composed of a bent and puckered crystalline sheet. Anhydrous sodium molybdate $\left(\mathrm{Na}_{2} \mathrm{MoO}_{4}\right)$ and hexagonal boron nitride (h-BN) powders were used as starting materials. This synthesis utilizing high pressure was carried out in a cubic DS $6 \times 14 \mathrm{MN}$ high-pressure apparatus. In the process of synthesis, the target pressure between 3 and $5 \mathrm{GPa}$ was maintained and temperature was in the range of $973-1,773 \mathrm{~K}$. The size of crystal was controlled using the reaction time and temperature. Figure 2 shows the onion-like structure of the $\delta$-MoN catalyst.

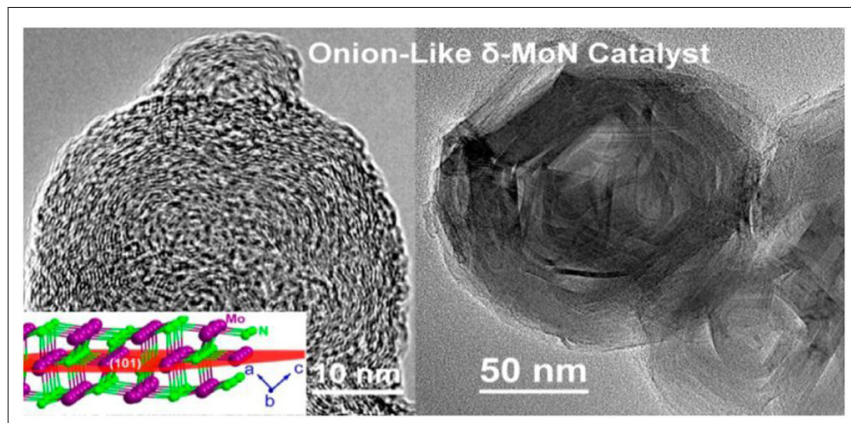

FIGURE 2 | Structure of $\delta$-MoN catalyst [Reproduced from Wang S. et al. (2017) with permission from ACS publications].

\section{Molten Salt Synthesis (MSS)}

MSS is a co-effective and very simple method for the synthesis of oxide powders and various ceramic materials. In this process of synthesis, molten salt enhances the fluidity of the reaction components in liquid phase that improves the rate of diffusion, and hence stops the aggregation of particles. This then results in a shortened reaction time and lower temperatures being required for the synthesis. Recently, MSS have been used for the synthesis of a variety of materials (Ding et al., 2014a,b, 2015, 2016; Zhang S. et al., 2014).

Metal nitrides have also been synthesized through molten salt synthesis. In the past, Ding et al. (2013) reported TiN wisker scan be synthesized using molten salt media on the graphitic surface. In this synthesis method, $\mathrm{Ti}$ metal, $\mathrm{NaF}$, and $\mathrm{NaCl}$ have been utilized as raw materials. 1:1, 1:2, 1:3, and 1:4 were the molar ratios of titanium to graphite, whereas the $\mathrm{NaCl}$ to $\mathrm{NaF}$ weight ratio was $10: 1 . \mathrm{NaF}$ and $\mathrm{NaCl}$ were added equally to $\mathrm{Ti}$ and graphite and were then mixed. Then the alumina crucible was used for the placement of the powder mixture and the temperature was maintained at $1,100-1,400^{\circ} \mathrm{C}$ for $3 \mathrm{~h}$ in a nitrogen atmosphere. After cooling, the solid mass was washed and filtered. The compound synthesized was characterized by XRD, SEM, and EDS.

\section{Reactive Sputtering Synthesis}

Reactive sputtering refers to the reactive sputter deposition where sputter-deposited vapor reacts on substrate with an ambient gas. Recently, this method has been used for the preparation of nanoparticles. In this method of synthesis, fewer impurities are generated than when using chemical methods. This is a versatile technique for the synthesis of ionic nanoparticles with spacious size. The drawback of this method is the gases used for sputtering can produce an effect on the morphology and optical properties.

Furthermore, Kang et al. (2015) synthesized $\mathrm{Ni}_{2} \mathrm{~N}$ by reactive sputtering of $\mathrm{Ni}$ under a nitrogen atmosphere at room temperature. This method led to the formation of $\mathrm{Ni}_{2} \mathrm{~N}$ film exhibiting a cauliflower-like nanostructure and tetrahedral crystal lattice. In this method of synthesis, $\mathrm{Ni}_{2} \mathrm{~N}$ counter electrodes were fabricated by sputtering of Ni on to FTO glass. The chamber was filled with $\mathrm{N}_{2}$ gas, and the reactive power was maintained at $150 \mathrm{~W}$ with a frequency of $13.56 \mathrm{MHz}$. Results showed that reactive sputtering is a reliable method for the preparation of nickel nitride counter electrodes at room temperature that can be used as a promising electrocatalyst for many applications, such as quantum dot-sensitized solar cells.

Sheng et al. (2018) reported high-entropy films with a composition of $\mathrm{NbTiAlSiN}_{\mathrm{x}} \mathrm{NbTiAlSiN}_{\mathrm{x}}$ film was synthesized using the reactive direct current (DC) magnetron sputtering technique with a varying flow rate of nitrogen gas. The properties of as-synthesized materials were characterized by XRD, SEM, HRTEM, spectrophotometer, and nano-indentor. $\mathrm{NbTiAlSiN}_{\mathrm{x}}$ films have been shown to have an amorphous structure and the films have shown thermal stability up to $700^{\circ} \mathrm{C}$. This film depicted absorption of solar energy in the wavelength 0.3$2.5 \mu \mathrm{m}$, which showed that $\mathrm{NbTiAlSiN}_{\mathrm{x}}$ film can be used as a solar selective absorbing coating for high-temperature photothermal conversion. 
Nickel is considered as a soft metal because of its properties such as oxidation and corrosion. In this respect, He et al. (2019) reported on the microstructure, corrosion, and mechanical properties of TiN/Ni nanomultilayered films. They synthesized nanomultilayered $\mathrm{TiN} / \mathrm{Ni}$ thin films by sputtering $\mathrm{Ti}$ and $\mathrm{Ni}$ targets in nitrogen gas atmospheres by changing the Ni layer deposition time. Deposition of $\mathrm{TiN}$ and $\mathrm{Ni}$ single layers was done under a bias voltage of $-70 \mathrm{~V}$; the top layer was the TiN layer. The microstructural and other properties of this film were investigated by XRD, FESEM, XPS, and electrochemical technologies. The mean grain size of the multilayer films was $8-9 \mathrm{~nm}$, which was considered independent of the bilayer period. The results showed that a decrease in both structural voids and thickness of the $\mathrm{Ni}$ single-layer are helpful for corrosion protection.

\section{Self Combustion Method}

Recently, Odahara et al. (2019) used a self-combustion method for the synthesis of ternary molybdenum nitrides. At room temperature, exothermic metathesis reaction occurs by mixing $\mathrm{NaNH}_{2}, \mathrm{MoCl}_{4}$, and $3 \mathrm{~d}$ transition metal chlorides, such as $\mathrm{MnCl}_{2}, \mathrm{FeCl}_{2}$, and $\mathrm{CoCl}_{2}$, that is driven thermodynamically by $\mathrm{NaCl}, \mathrm{N}_{2}$, and $\mathrm{NH}_{3}$ formation. As a result, the combustion process yielded a ternary rock salt $\gamma-\mathrm{TM}_{\mathrm{X}} \mathrm{Mo}_{1-\mathrm{x}} \mathrm{N}_{0.5}$ nanoparticle $(\mathrm{TM}=\mathrm{Mn}, \mathrm{Fe}, \mathrm{Co})$. From DFT studies, it was concluded that ternary molybdenum nitrides that are synthesized by this method are thermodynamically stable at high temperatures but metastable at ambient conditions.

\section{Chemical Reduction}

In the chemical reduction method, ionic salt is reduced in an appropriate medium in the presence of surfactants using different reducing agents. This is the simplest method for the preparation of metal nanoparticles. Several limitations are associated with reducing agents such as toxicity, purity, the high costs involved, etc.

Panda and Gajbhiye (1997) synthesized iron nitrides via $\alpha$ Fe nitridation by utilizing ammonia as a nitrogen $\left(\mathrm{N}_{2}\right)$ source. As a result, iron nitrides were synthesized because of the decomposition of ammonia. In this method, iron is an active catalyst for the synthesis of $\mathrm{NH}_{3}$. This creates the possibility of nitrogen atoms occurring, formed at increased pressure to enter into $\alpha$-Fe lattice forming nitrides at an elevated temperature. By using $\mathrm{Fe}$ (iron) in an amorphous form as a starting material, $\mathrm{Fe}_{3} \mathrm{~N}$ is synthesized.

\section{Salt-Templated Method}

Similarly, Xiao et al. (2017) reported the salt-templated synthesis of metallic 2D metallic MoN. 2D MoN was synthesized by the reduction of $2 \mathrm{D}$ hexagonal oxides in ammonia at $650^{\circ} \mathrm{C}$. Annealing of Mo precursor@ $\mathrm{NaCl}$ powders at $280^{\circ} \mathrm{C}$ in an $\mathrm{Ar}$ atmosphere occurred to produce $2 \mathrm{D}$ hexagonal $\mathrm{MoO}_{3}$ coated $\mathrm{NaCl}$. To avoid the morphology change that occurs during the conversion of $\mathrm{h}-\mathrm{MoO}_{3}$ to $\mathrm{MoN}$, salt is added as a stabilizer. XRD reveals the crystal structure of hexagonal MoN, and XPS (Xray photoelectron spectroscopy) confirms the presence of Mo and $\mathrm{N}$. The tyndall scattering effect confirmed that 2D MoN nanosheets showed a good dispersity in deionized water with a zeta potential of $-32 \mathrm{mV}$, resulting in a colloidal solution. Figure 3 shows the schematic representation for synthesis of 2D MoN.

Similarly, Jin H. et al. (2018) utilized the Ni induced salt template method to synthesize $2 \mathrm{D} \mathrm{Mo}_{5} \mathrm{~N}_{6}$ nanosheets. In this method, nickel acetate and $\mathrm{MoO}(\mathrm{OH})_{\mathrm{x}}$ were used as starting materials. It was seen that regular $\mathrm{MoN}$ can be synthesized without adding $\mathrm{Ni}$ salt. The incorporation of nitrogen atoms in the lattice of $\mathrm{Mo}_{5} \mathrm{~N}_{6}$ altered its inherent properties, which led to a higher Mo valence state and an electronic structure like Pt. Figure 4 illustrates the synthesis of $\mathrm{MoN}$ and $\mathrm{Mo}_{5} \mathrm{~N}_{6}$ nanosheets through an ammonization synthesis with and without the addition of $\mathrm{Ni}$ in the precursor.

Similarly, Kan et al. (2017) reported the synthesis of nanoscale titanium nitride. In this case, the molten salt mediated reduction method was used; the heating rate for the reaction was 600$1,100^{\circ} \mathrm{C}$ for $1-7 \mathrm{~h}$ in an atmosphere provided with nitrogen. $\mathrm{TiO}_{2}$ (Titanium dioxide) and $\mathrm{Mg}$ powders were used as starting materials. Phase composition, morphology of a structure, particle size, and surface area were characterized by SEM, TEM, BET specific-surface area analysis, and XRD. The results showed that TiN crystals synthesized using this method of synthesis were $\sim 5-30 \mathrm{~nm}$ in size, and their specific surface area was about 76.47-93.09 $\mathrm{m}^{2} / \mathrm{g}$, higher than $\mathrm{TiO}_{2}\left(9.83 \mathrm{~m}^{2} / \mathrm{g}\right)$. This method of synthesis was proved to be useful, as salt is not involved in the reaction with the product and can be easily removed as it is soluble in water at low temperatures.

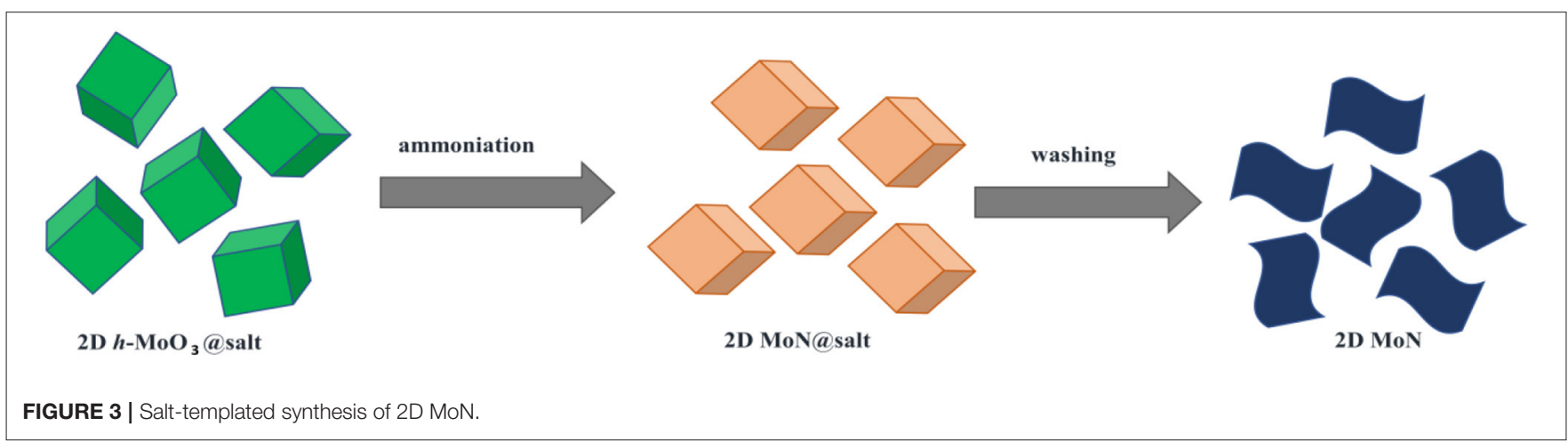




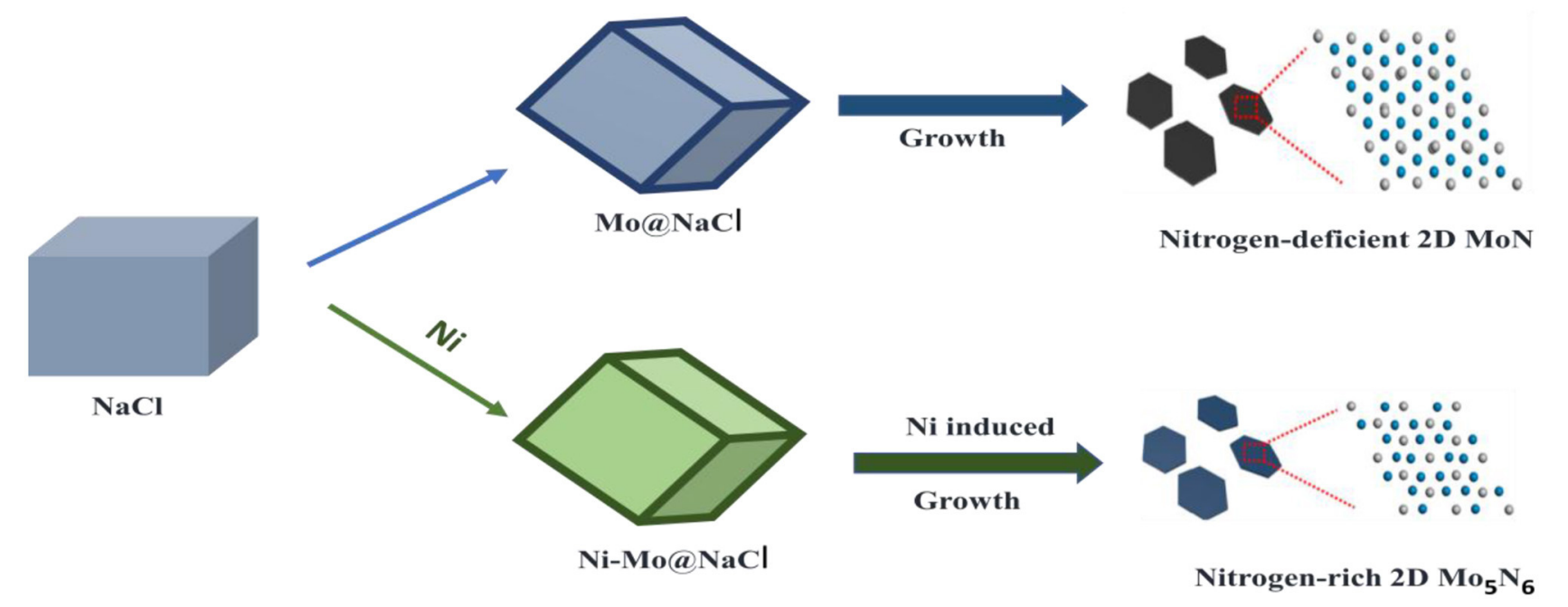

FIGURE 4 | Synthesis of $\mathrm{MoN}$ and $\mathrm{Mo}_{5} \mathrm{~N}_{6}$ nanosheets.

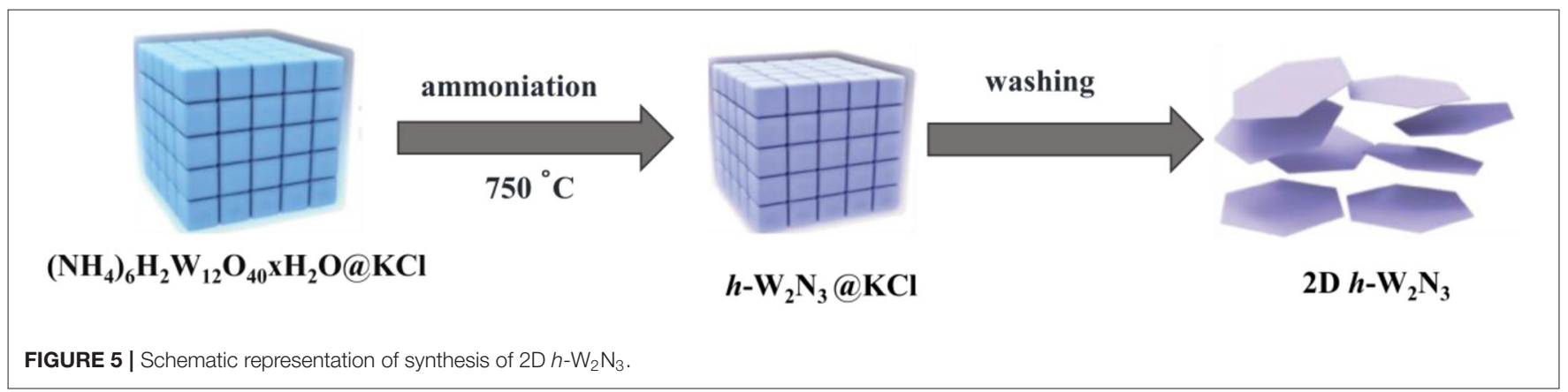

In 2018, Yu et al. (2018) utilized the salt-templated method for synthesis of a thin $2 \mathrm{D}$ nitrogen rich hexagonal tungsten nitride $\left(h-\mathrm{W}_{2} \mathrm{~N}_{3}\right)$. In this method of synthesis, coating of $\left(\mathrm{NH}_{4}\right)_{6} \mathrm{H}_{2} \mathrm{~W}_{12} \mathrm{O}_{40} \cdot x \mathrm{H}_{2} \mathrm{O}$ on the surface of $\mathrm{KCl}$ $\left(\left(\mathrm{NH}_{4}\right)_{6} \mathrm{H}_{2} \mathrm{~W}_{12} \mathrm{O}_{40} \cdot x \mathrm{H}_{2} \mathrm{O} @ \mathrm{KCl}\right)$ was carried out to obtain the precursor. This synthesized precursor was then ammoniated at about $750^{\circ} \mathrm{C}$ in the presence of an ammonia atmosphere. After dissolution and removal of $\mathrm{KCl}$ salt template in deionized water, $2 \mathrm{D} h-\mathrm{W}_{2} \mathrm{~N}_{3}$ were obtained. Its $2 \mathrm{D}$ morphology was identified by STEM. This 2D $h-\mathrm{W}_{2} \mathrm{~N}_{3}$ showed a size of around $5 \mu \mathrm{m}$ with a thickness of $1.5 \mathrm{~nm}$. Figure 5 represents a schematic representation of the synthesis of $2 \mathrm{D} h-\mathrm{W}_{2} \mathrm{~N}_{3}$.

\section{Solution Combustion Synthesis (SCS)}

The SCS method involves an exothermal redox reaction between fuel and oxidizers, and the heat that is released from the redox reaction provides energy to sustain a combustion reaction. This method involves large scale synthesis and also requires less time.

$\mathrm{Wu}$ et al. (2019) synthesized 2D VN nanoparticles/carbon sheet nanocomposites using solution combustion synthesis (SCS) and the ammonia reduction method. Many nanostructure VNs have been synthesized, but the method of synthesis used requires specialized equipment, a greater time for synthesis, and high temperatures. The SCS process helps in the uniform adhering of vanadium oxide particles on carbon sheets. The precursors used in the SCS process were ammonium metavandate, ammonium nitrate, gylcine, citric acid, and glucose, which were dissolved in DI water and then the resulting solution was heated in an electric heating furnace. The resulting products (vanadium oxide carbon precursor and vanadium nitride/carbon) were calcined for $2 \mathrm{~h}$ at $700^{\circ} \mathrm{C}$. The ammonia reduction process was carried out in a tube furnace with a flow of ammonia gas, at a constant heating rate of $8^{\circ} \mathrm{C} \mathrm{min} \mathrm{m}^{-1}$ for $2 \mathrm{~h}$ in the range of $600-800^{\circ} \mathrm{C}$. This method has the ability for large-scale production of other metal nitrides such as WN, TiN, and their nanocomposites with carbon for high performance electrode materials.

\section{In-situ Growth Method}

This is a simple and effective route to synthesize nanocomposites. This method allows the one-step synthesis of nanocomposites with in-situ generated particles from corresponding reactants. With this method it is hard to control the size and morphology of nanocomposites.

He et al. (2020) reported the fabrication of molybdenum nitride $\left(\mathrm{Mo}_{2} \mathrm{~N}\right)$ quantum dots embedded in polyaniline for application in a supercapacitor. Polyaniline was selected 
as it has excellent electrochemical properties. $\mathrm{Mo}_{2} \mathrm{~N}$ was synthesized by dissolving ammonium molybdate tetrahydrate and hexamethylene (HMT) in deionized water. Precipitates of white crystals were collected and heated in a tube furnace at $800^{\circ} \mathrm{C}$ for $2 \mathrm{~h}$ at a rate of $5^{\circ} \mathrm{C} / \mathrm{min}$ in the atmosphere of nitrogen gas. Similarly, a composite of $\mathrm{Mo}_{2} \mathrm{~N}$ with polyaniline was synthesized by dissolving $\mathrm{Mo}_{2} \mathrm{~N}$ and $\mathrm{ANI}$ in molar solution of $\mathrm{HCl}$. The resulting solution was mixed with ammonium persulfate for $12 \mathrm{~h}$ to obtain the composite of $\mathrm{Mo}_{2} \mathrm{~N}$. The synthesized $\mathrm{Mo}_{2} \mathrm{~N} @ \mathrm{PANI}$ composite was confirmed by FTIR, $\mathrm{XRD}, \mathrm{XRF}$, and TEM techniques. Figure $\mathbf{6}$ shows the scheme for the synthesis of the $\mathrm{Mo}_{2} \mathrm{~N} @ \mathrm{PANI}$ composite.

\section{Chemical Vapor Deposition (CVD) Method}

CVD is a very old method used for the synthesis of oxides, carbides, nitrides, borides, etc. In the CVD method of synthesis, a chemical reaction is induced in a gas phase at different temperatures. This method occurs in three steps. In the first step, kinetically-controlled deposition occurs, then limited diffusion growth occurs in the second step. In the last step, depletion of the diffusion zone above the substrate occurs. CVD is helpful in the synthesis of a variety of materials as it varies chemical composition and synthesis conditions like pressure and temperature. Materials of different morphologies and space arrangements are synthesized. Doping of different atoms can be done using CVD.

In this respect, Xi et al. (2019) synthesized a single crystal of MoN using the chemical vaporization technique. The structural coherence in single crystalline MoN helps to confine active sites that are ordered with unsaturated nitrogen coordination in a crystal lattice, which creates an electrochemically active surface for fast oxidation-reduction reactions. MoN was synthesized by treating a single crystal of $\mathrm{PbMoO}_{4}$ in an $\mathrm{NH}_{3}$ atmosphere using the chemical vapor deposition system. Ammonia gas was passed at a flow rate of $600 \mathrm{mLmin}^{-1}$.

Similarly, Zhang J. et al. (2014) synthesized a nitrogen doped TiN composite using homogeneous distribution on the surface and in the bulk of spinel lithium titanite with the chemical vapor deposition technique. This one step synthesis was carried out by using ethylenediamine as a nitrogen source and lithium titanite as a titanium source.

2D nanocomposites have attracted worldwide attention and promises to have use in many applications, unlike other photocatalytic materials, because of their excellent properties (Zhao et al., 2018a,b). 2D hexagonal nitride nanosheets are attracting interest in catalytic applications because of their excellent adsorption and photooxidation resistance performance. In this regard, Zhao et al. (2019) doped sulfur atoms into hexagonal boron nitride nanosheets (h BNN) with the CVD method and bandgap $(4.13 \mathrm{eV})$ adjustment was realized by a dopant atom, which enabled h-BNN to exhibit excellent visible light photocatalytic activity. Their results showed that this non-metallic catalyst could have very good applications for environmental protection.

\section{Wet Chemical Etching Method}

Wet chemical etching is a material removal process that utilizes etchants or liquid chemicals to remove materials from wafers. This method involves many chemical reactions that consume original reactants and produce new products. This is a cheap and straightforward route to chemical etching.

During this process, strong acids such as $\mathrm{HF}, \mathrm{HCl}$, and $\mathrm{HNO}_{3}$ are used as etching solvents, although they are extremely hazardous. This method requires a greater amount of etching chemicals because substrate materials have to be covered with an etchant chemical.

Venkateshalu and Grace (2020) synthesized $\mathrm{Ti}_{3} \mathrm{C}_{2} \mathrm{~T}_{\mathrm{X}}$ MXene and vanadium nitride/Porous carbon (VN/PC) as an electrode for asymmetric supercapacitors in which $\mathrm{Ti}_{3} \mathrm{C}_{2} \mathrm{~T}_{\mathrm{X}}$ acts as a negative electrode and VN/PC as a positive electrode. $\mathrm{Ti}_{3} \mathrm{C}_{2} \mathrm{~T}_{\mathrm{X}} \mathrm{MXene}$ was synthesized using a one-step reaction in which etching of the $\mathrm{Al}$ layer in $\mathrm{Ti}_{3} \mathrm{AlC}_{2}$ was carried out by immersing them in $40 \% \mathrm{HF}$ and further delaminated with DMSO. VN/PC was synthesized using the reported method with some small changes (Yang Y. et al., 2017), in which $\mathrm{V}_{2} \mathrm{O}_{5}$ was added in $\mathrm{H}_{2} \mathrm{O}_{2}$, dissolved in DI water, and was stirred for about $2 \mathrm{~h}$ to form a gel known as xerogel. Later on, this gel was mixed with melamine and was transferred to a tube furnace in the presence of $\mathrm{N}_{2}$ to obtain black VN/CN.

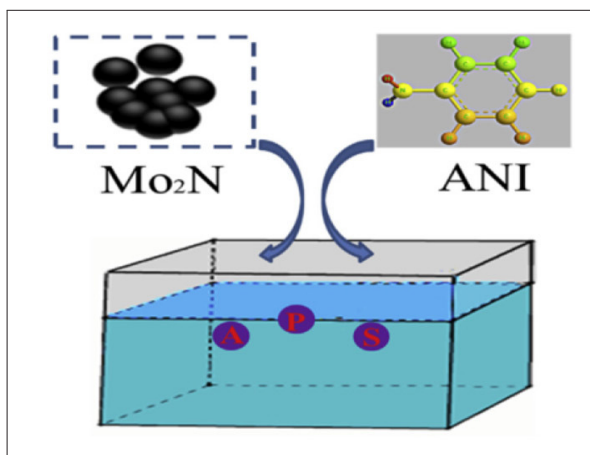

\section{$12 \mathrm{hr}$ stirring at room temperature}

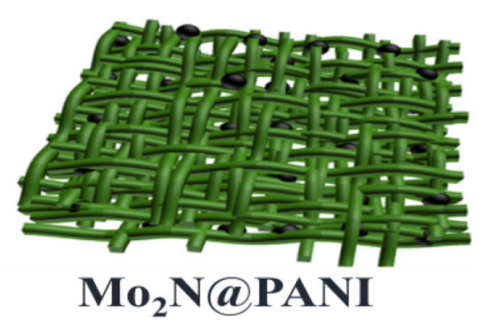

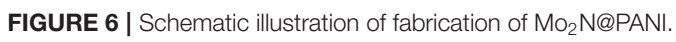




\section{Electrospinning Method}

Electrospinning is a simple and versatile method, mainly used for the synthesis of nanofibers. In this method, a high voltage of electricity is applied to the liquid solution and a collector. Inorganic fibers can also be prepared with this method using polymers. The length and diameter of the nanofiber largely depends upon the liquid, voltage, flow rate, and distance between the tips of the spinneret and the receiving equipment.

The drawback of this method is that the presence of polymers may change surface tension and other properties of the electrospinning solution, which are critical for the electrospinning process. Solvents used in this method may be toxic and 3D structures can't be synthesized by this method of synthesis.

$\mathrm{Xu}$ et al. (2019) reported the synthesis of $\mathrm{TiN} @ \mathrm{MnO}_{2}$ using the electrospinning method. Electrospinning is considered to be a versatile technique for synthesizing $1 \mathrm{D}$ nanofibers. TiN shows a higher electrical conductivity of 4,000-55,500 S/cm and greater mechanical stability. 1D nanostructure is attractive for electrochemical applications. These properties enabled them to construct a 1D nanostructured composite of 1D TiN and $\mathrm{MnO}_{2}$ hybrid nanocomposite for electrochemical energy storage. This composite showed enhanced electrochemical properties. TiN nanofibers were prepared through the nitridation electrospinning of a $\mathrm{TiO}_{2}$ nanofiber by ammonia annealing. For fabrication of the TiN@ $\mathrm{MnO}_{2}$ nanocomposite, a solution of TiN in deionized water and $\mathrm{KMnO}_{4}$ was hydrothermally treated for $5 \mathrm{~h}$ at $160^{\circ} \mathrm{C}$. Hence, the electrospinning method can be used for the fabrication of metal nitrides with the morphology of nanofibers.

\section{Atomic Layer Deposition (ALD)}

ALD is a thin film deposition technique that is based on the use of the gas phase chemical process. The majority of ALD reaction uses precursor molecule that reacts with the surface of substrate in a self limiting manner. This is a slow technique, in which surface contamination occurs that results in the surface defects of films that can't be repaired.

In a related development, Song et al. (2019) adopted the atomic layer deposition method for fabricating TiN nanoparticles into carbon nanotubes (CNTs) for the utilization of Pt electrocatalyst support because of its good stability and conductivity of TiN. Atomic layer deposition has the ability to produce very thin and uniform films with precise control over the composition and thickness at an atomic level. It was found that TiN nanoparticles synthesized from atomic layer deposition that have a $20 \mathrm{~nm}$ diameter were immobilized homogeneously on CNTs. TiN was synthesized by $\mathrm{TiCl}_{4}$ and $\mathrm{NH}_{3}$ vapors in a reaction chamber with nitrogen gas of a high purity. A Pt nanoparticle was deposited by the reported ethylene glycol reduction method (Higgins et al., 2012; Liu G. et al., 2017).

\section{APPLICATIONS}

Metal nitrides are very well-known for their hardness, high conductivity, and refractoriness. These unique properties make metal nitrades suitable for use in thermocouple sheaths, crucibles, and cutter coatings. Furthermore, catalytic applications of metal nitrides have been discovered in the last century. For example, iron nitrides have been used as a Fischer-Tropsch catalyst. Moreover, it was seen that nitrogen has the ability to replace carbon atoms in most metal carbides, forming nitrogen doped metal carbides. In respect to the widely studied applications of metal nitrides herein, we offer recent advances on the applications of metal nitrides in energy storage.

\section{Water Splitting}

Hydrogen produced via direct water splitting using a semiconductor photocatalyst in the presence of sunlight is considered to be an alternative energy source for fossil fuels and a solution for many serious environmental problems. Photocatalytic water splitting involves the generation of electrons and holes by a photocatalyst by the absorbing of solar energy, migration of electrons and holes to the surface of the semiconductor, and formation of $\mathrm{H}_{2}$ and $\mathrm{O}_{2}$ on the surface by the redox reaction of water.

$\mathrm{GaN}$ surfaces have the capacity for both $\mathrm{H}_{2}$ and $\mathrm{O}_{2}$ evolution. In 2017, Wang et al. (2011) reported that the incorporation of a photodeposited $\mathrm{Rh} / \mathrm{Cr}_{2} \mathrm{O}_{3}$ core-shell structure as a cocatalyst in $\mathrm{GaN}$ showed photocatalytic pure water splitting. This work showed that a III nitride nanowire heterostructure can be used as a feasible photocatalyst for efficient water splitting and generation of $\mathrm{H}_{2}$ directly from solar irradiation. A scheme of the pure water splitting process by GaN nanowires is illustrated in Figure 7.

Similarly, in 2013, Kibria et al. (2013) reported that InGaN can also be used as a new material for the production of solar fuels through photochemical water splitting under direct ultraviolet and visible light irradiation. Multi-bands of InGaN/GaN nanowire incorporated with $\mathrm{Rh} / \mathrm{Cr}_{2} \mathrm{O}_{3}$ core-shell nanoparticles leads to hydrogen production from water splitting under UV (ultra-violet), blue, and green-light irradiation (upto $560 \mathrm{~nm}$ ).

In 2015, Shalom et al. (2015) reported on the synthesis of nickel nitride $\left(\mathrm{NiN}_{3}\right)$ and its application for water splitting. In

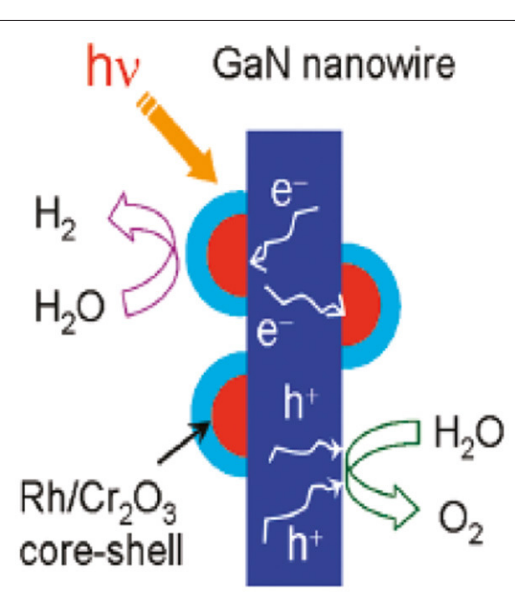

FIGURE 7 | Schematic illustration of water splitting on GaN nanowires by incorporating a $\mathrm{Rh} / \mathrm{Cr}_{2} \mathrm{O}_{3}$ core- shell nanostructure as a cocatalyst [Reproduced from Wang et al. (2011) with permission from ACS publications]. 


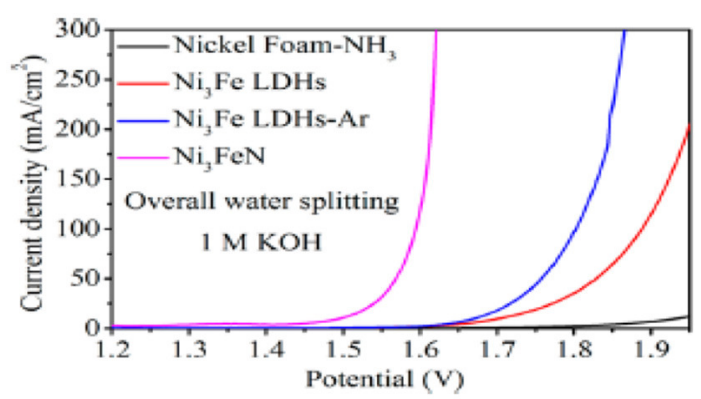

FIGURE 8 | LSV curves for overall water splitting for NSP-NiFeN in a two-electrode system having a scan rate of $2 \mathrm{mV} / \mathrm{s}$ [Reproduced from Wang et al. (2016) with permission from ACS publications].

this method, modification of an Ni-foam surface with an $\mathrm{Ni}_{3} \mathrm{~N}$ layer was done for electrocatalytic application. The modification of the foam resulted in a 5-fold increase of surface area as well as an increase of active $\mathrm{Ni}^{2+}$ species more than 50 times. The modified foam showed lower overpotential, good stability, and higher current densities for hydrogen evolution reaction (HER) in alkaline solutions.

Similarly, Wang et al. (2016) reported a synthesis of highly efficient nanoparticle-stacked porous (NSP) $\mathrm{Ni}_{3} \mathrm{FeN}$ nanosheets for water splitting. Nanosheets possess active sites that were used for an electrocatalytic reaction. Hence, it showed outstanding performance for oxygen evolution reaction (OER), having an extremely lower overpotential of $223 \mathrm{mV}$ at $10 \mathrm{~mA} / \mathrm{cm}^{2}$ and HER with an overpotential of $45 \mathrm{mV}$ at $10 \mathrm{~mA} / \mathrm{cm}^{2}$. For water splitting, $\mathrm{Ni}_{3} \mathrm{FeN}$ as a bifunctional catalyst needs a very small cell voltage of only $1.49 \mathrm{~V}$ to reach $10 \mathrm{~mA} / \mathrm{cm}^{2}$ in $1 \mathrm{M} \mathrm{KOH}$. Figure 8 shows the water splitting of NSP-NiFeN in a two-electrode system. This electrocatalyst is reported for overall water splitting in an alkaline media.

Similarly, Zhang B. et al. (2016) reported in-situ growth of an iron-nickel nitride nanostructure that was carried out on surface-redox etching $\mathrm{Ni}$ foam $\left(\mathrm{FeNi}_{3} \mathrm{~N} / \mathrm{NF}\right)$ and was used as a bifunctional electrocatalyst for overall water splitting. It was reported that $\mathrm{FeNi}_{3} \mathrm{~N} / \mathrm{NF}$ showed excellent activity for both HER and OER with low overpotential of 75 and $202 \mathrm{mV}$ at $10 \mathrm{~mA}$

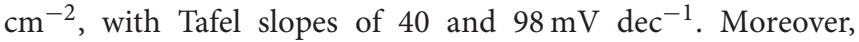
it was also reported that the $\mathrm{FeNi}_{3} \mathrm{~N} / \mathrm{NF}$ catalyst showed good durability, reflecting $>400 \mathrm{~h}$ of consistent galvanostatic electrolysis without any visible voltage elevation.

Furthermore, Zhu et al. (2018) reported on the synthesis of hierarchical Ni-Fe-Mo trimetal nitride nanotube (NTs) for water splitting application. It was seen that the incorporation of iron $(\mathrm{Fe})$ enhanced HER and OER activities of nanotubes. Hence, trimetal nitride nanotubes showed outstanding activities toward both HER and OER having a $10 \mathrm{~mA} \mathrm{~cm}{ }^{2}$ current density at OER and 228 and $55 \mathrm{mV}$ HER overpotentials. It was reported that the two-electrode electrolyzer assembled from hierarchical trimetal nitride nanotubes has the capacity to drive a current density of $10 \mathrm{~mA} \mathrm{~cm} \mathrm{~cm}^{2}$ at $1.513 \mathrm{~V}$, outperforming $\mathrm{IrO}_{2} \mid$ Pt couple.

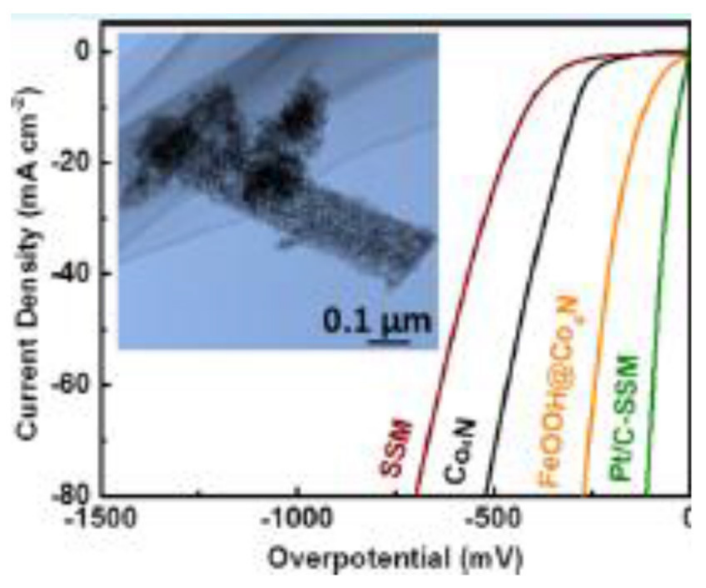

FIGURE 9 | HER polarization curves [Reproduced from Hu et al. (2019) with permission from ACS publications].

Recently, $\mathrm{Hu}$ et al. (2019) reported that by tuning dorbitals of $\mathrm{Co}_{4} \mathrm{~N}$ nanowires through the incorporation of iron oxyhydroxide $(\mathrm{FeOOH})$, the HER electrocatalytic property can be enhanced. They reported an FeOOH@ $\mathrm{Co}_{4} \mathrm{~N}$ hybrid electrocatalyst exhibited excellent activity by displaying a low overpotential at $10 \mathrm{~mA} \mathrm{~cm}^{-2}$ of $92 \mathrm{mV}$, with a small Tafel slope of $34 \mathrm{mV} \mathrm{dec}^{-1}$. After theoretical analysis, it was confirmed that enhanced HER activity of FeOOH@ $\mathrm{Co}_{4} \mathrm{~N}$ occurred because of greater electronic interaction between $\mathrm{Co}_{4} \mathrm{~N}$ and $\mathrm{FeOOH}$, and hence led to increased HER kinetics. The following Figure 9 shows the polarization curve of HER FeOOH@ $\mathrm{Co}_{4} \mathrm{~N}$.

Mohamed et al. (2020) synthesized TiN/TiO ${ }_{x} \mathrm{~N}_{y}$ bilayer films using D.C reactive magnetron sputtering. Li et al. (2015) reported that in a bilayer film a higher TiN layer causes a more negative flat -band value. In the case of water splitting, a more negative band value helps to provide a larger driving force to trigger water redox. In this work it is reported that the bilayer films exhibited onset potential at around $-0.6 \mathrm{~V} \mathrm{Ag} / \mathrm{AgCl}$. Above this value it was seen that the photocurrent density is increased with increasing voltage. This increase in voltage occurred because of greater charge separation and enhanced charge transfer. Photocurrent density was increased with an increasing TiN top layer with a thickness of $9 \mathrm{~nm}$. This showed that the heterojunction of these two materials could increase synergetic effects to PEC performance.

Bimetallic nitrides oxynitrides with large numbers of catalytically active sites have found an ideal substrate for energy conversion. Looking at this point, Dutta et al. (2019) synthesized cobalt nitride vanadium oxynitride nanohybrid by using the polyaniline (PANI) synthetic protocol. This nanohybrid showed a greater electrochemical performance when compared with cobalt nitride vanadium oxynitride and many noble metal catalysts. For OER, only $263 \mathrm{mV}$ overpotential was required to attain a current density of $10 \mathrm{~mA} \mathrm{~cm} \mathrm{~cm}^{-2}$ and $118 \mathrm{mV}$ for HER. For overall alkaline water splitting, a cell voltage of $1.64 \mathrm{~V}$ was required to attain a current density of $10 \mathrm{~mA} \mathrm{~cm}^{-2}$ with long 
term stability of $100 \mathrm{~h}$. Incorporation of vanadium oxynitride in cobalt nitride that acts as an electrocatalyst helps in the generation of large numbers of active sites, which enhanced water splitting activity. This work will be helpful in designing new transition metal nitride-oxynitride hybrids for efficient, low-cost, and durable electrocatalysts for water splitting in industries.

Yin et al. (2019) used Co-doped MoNi nitride nanowire (NW) for water splitting. After doping cobalt in this trimetal nitride, the active surface area is enhanced and electrical conductivity is increased, which leads the porous Co-doped MoNi nitride to exhibit high activity and display good stability for HER, OER, and ORR. A co-doped nanowire displayed high activities for HER and OER with OER and HER overpotentials of 294 and $45 \mathrm{mV}$ at $10 \mathrm{~mA} / \mathrm{cm}^{2}$ in $1 \mathrm{M} \mathrm{KOH}$ solution. The electrolyzer assembled by Co doped NW delivers $10 \mathrm{~mA} / \mathrm{cm}^{2}$ at $1.57 \mathrm{~V}$ when compared to $\mathrm{IrO}_{2} \mid \mathrm{Pt}$ couple. In $0.1 \mathrm{M} \mathrm{KOH}$, this $\mathrm{NW}$ showed good ORR catalytic activity.

\section{Supercapacitors}

Supercapacitors (SCs) are considered to be one of the most potent candidates for energy storage. They have gathered greater attention because of the urgent and increasing need for and development of renewable energies. They are seen to be an efficient energy storage device for hybrid electric vehicles, portable electronics, and memory back-up systems (Guan et al., 2012; Rakhi et al., 2012; Wang et al., 2012). Metal nitrides (e.g., TiN, VN, etc.) can be used as excellent electrode materials because of their high specific capacitance and outstanding electrical conductivity (Lu et al., 2012).

Dong et al. (2011) reported synthesis of TiN/VN coreshell composites. These composites were reported to show outstanding electrical conductivity and excellent capacity storage. It was reported that higher specific capacitance $\left(170 \mathrm{~F} \mathrm{~g}^{-1}\right)$ was obtained at a $2 \mathrm{mV} \mathrm{s}^{-1}$ scan rate and displayed a remarkable rate capacity. TiN/VN shows the highest specific capacitance of $170 \mathrm{~F} \mathrm{~g}^{-1}$ with a $2 \mathrm{mVs}^{-1}$ scan rate. The core-shell TiN/VN fiber introduced a mesoporous structure into the high-conductivity nitriding hybrid, which combined the higher specific capacitance of $\mathrm{VN}$ and better rate performance of TiN. Therefore, the combination of $\mathrm{VN}$ and $\mathrm{TiN}$ into fast-mixed nanocomposites can be expected to provide electrochemical storage materials in future.

Lu et al. (2012) reported that the stabilization of TiN can occur without decreasing its electrochemical performance, and this can be done by using poly vinyl alcohol (PVA)/KOH gel as an electrolyte. This electrode made up of polymers helps to suppress the oxidation reaction on the surface of electrodes. After performing electrochemical studies, it was seen that solid state TiN super capacitors showed outstanding stability up to 15,000 cycles and hence achieved a high volumetric energy density of $0.05 \mathrm{mWh} / \mathrm{cm}^{3}$. The TiN electrode exhibited improved stability than that of the TiN electrode in $1 \mathrm{M} \mathrm{KOH}$ aqueous electrolyte as depicted in Figure 10.

Molybdenum-based composite materials have shown outstanding electrochemical performance when used as supercapacitors because of their increased surface area and good cycling stability (Zhao et al., 2020). Das et al. (2015) reported

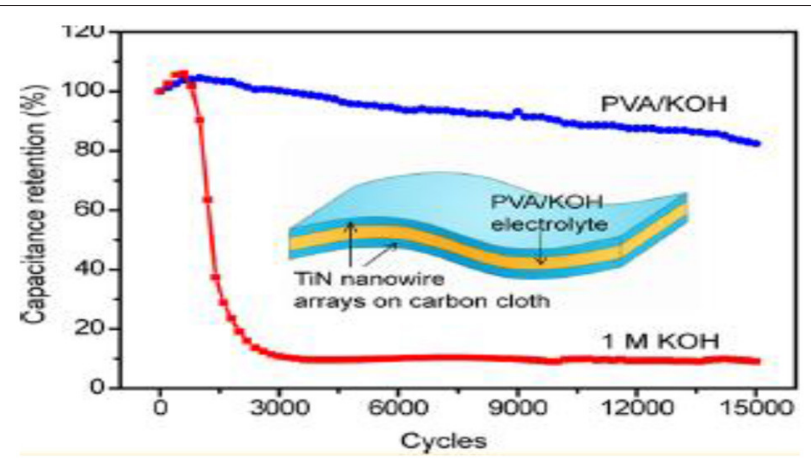

FIGURE 10 | Cyclic performance for TiN-SC with PVA/KOH at $100 \mathrm{mV} / \mathrm{s}$ scan rate and 1 molar $\mathrm{KOH}$ aqueous electrolyte [Reproduced from Lu et al. (2012) with permission from ACS publications].

that single crystalline $\mathrm{Mo}_{2} \mathrm{~N}$ nanobelts can be synthesized using a slow nitride solid state reaction. It was reported that the $\mathrm{Mo}_{2} \mathrm{~N}$ nanobelts, which are porous, showed a high specific capacitance of $160 \mathrm{~F} / \mathrm{g}$, high rate capability, and good cyclic stability even at high scanning rates of $100 \mathrm{mVs}^{-1}$ as a supercapacitor electrode material.

Achour et al. (2017) reported that a titanium vanadium nitride (TiVN) electrode can be used as an electrode material for microsupercapacitors. A TiVN electrode exhibited an areal capacitance value of $15 \mathrm{mF} \mathrm{cm}^{-2}$ at $2 \mathrm{mVs}^{-1}$ with extraordinary capacitance retention of more than $99 \%$ after 10,000 cycles.

Wei et al. (2018) reported porous $\mathrm{CrN}$ to have outstanding electrical conductivity and a higher surface area, exhibiting a higher electrochemical performance. This porous $\mathrm{CrN}$ showed a $31.3 \mathrm{mF} \mathrm{cm}^{-2}$ specific capacitance at $1.0 \mathrm{~mA} \mathrm{~cm}^{-2}$ with excellent cycling stability, having a capacitance retention of $94 \%$ over 20,000 cycles. Moreover, this porous CrN electrode also showed to have a greater energy density of $14.4 \mathrm{mWh} \mathrm{cm}^{-3}$ at a power density of $0.3 \mathrm{~W} \mathrm{~cm}^{-3}$. Similarly, Shen et al. (2018) investigated that $\mathrm{NbN}$ thin films can be used as a promising candidate for supercapacitors. These electrodes have the ability to achieve a $707.1 \mathrm{~F} \mathrm{~cm}^{-3}$ volumetric capacitance and also showed cycling stability with a capacitance retention of $92.9 \%$ after 20,000 cycles.

Gao Z. et al. (2019) synthesized plasma-etched HfN. It was seen that this $\mathrm{HfN}$ exhibited a higher capacitance of $5.6 \mathrm{mF}^{-2}$ at $1.0 \mathrm{~mA} \mathrm{~cm}{ }^{-2}$ and showed an outstanding cycling life, which demonstrates its use in supercapacitor applications. Results showed the specific capacitance of $\mathrm{H} 2$ film that is calculated from the discharge curve is $5.6 \mathrm{Mf} \mathrm{cm}^{-2}$ at $0.2 \mathrm{~mA} \mathrm{~cm}^{-2}$, which is 8 times higher than $\mathrm{H} 1$ film. As-deposited $\mathrm{HfN}$ is named $\mathrm{H} 1$ and plasma-etched $\mathrm{HfN}$ is named $\mathrm{H} 2$.

More recently, $\mathrm{He}$ et al. (2020) reported $\mathrm{Mo}_{2} \mathrm{~N}$ synthesis with polyaniline that can act as an electrode material for use in a supercapacitor. The $\mathrm{Mo}_{2} \mathrm{~N} @ \mathrm{PANI}$ composite material shows higher specific capacitance with the current density at $0.5 \mathrm{~A} / \mathrm{g}$, having a specific capacity of 111.8 F/g. $\mathrm{Mo}_{2} \mathrm{~N} @ P A N I$, which shows a much higher rate performance of $66.4 \%$.

Xu et al. (2019) synthesized a TiN@MnO 2 nanocomposite for its application in supercapacitors. This nanocomposite showed 
enhanced electrochemical properties having a high specific capacitance of $386 \mathrm{~F} / \mathrm{g}$ at a current density of $1 \mathrm{~A} / \mathrm{g}$ with cyclic stability of $111.7 \%$ capacity retention after 4,000 cycles at $6 \mathrm{~A} / \mathrm{g}$. These unique nanostructures were responsible for showing good electrochemical performance. High electrical conductivity of TiN and hierarchical $\mathrm{MnO}_{2}$ nanosheets are responsible for greater charge transfer, and hence offer more electroactive sites available for redox reaction, which demonstrate the good electrochemical properties of this nanocomposite (Xu et al., 2019).

Metal nitrides such as titanium nitride (TiN), vanadium nitride $(\mathrm{VN})$, and tungsten nitride $(\mathrm{WN})$ have been investigated as powerful anode materials for SCs. Among them, it was seen that $\mathrm{VN}$ exhibited a high specific capacitance of $1,340 \mathrm{~F} / \mathrm{g}$ ( $\mathrm{Lu}$ et al., 2013; Balogun et al., 2015; Wang et al., 2015) that may occur because of a combination of pseudocapacitance and double layer type capacitance.

In this regard, Wu et al. (2019) synthesized a $2 \mathrm{D} \mathrm{VN}$ nanoparticles/carbon sheet nanocomposite using solution combustion synthesis. This as-synthesized nanocomposite displayed a good specific capacitance of 249 and $192 \mathrm{~F} / \mathrm{g}$ at 0.1 and $1 \mathrm{~A} / \mathrm{g}$ by using $1 \mathrm{M} \mathrm{KOH}$ as an electrolyte. Furthermore, this nanocomposite exhibited a good cycling stability of $75.8 \%$ after 5,000 cycles. This nanocomposite resulted in good electrochemical properties, as the carbon sheet has the ability to act as an electron transport medium and also has excellent interfacial contact between VN nanoparticles and carbon sheets. The capacitance of various metal nitride composites is reported in Table 1.

Asymmetric devices are hybrid SCs that have two different electrode materials which have the ability to show different charge storage mechanisms. Asymmetric SCs exhibit a greater potential window and also operate at higher voltages. These properties are not found in symmetric SCs. The potential window in asymmetric SCs can be extended beyond the thermodynamic decomposition voltage of electrolytes that is currently used, and hence they have the ability to overcome the energy storage limitation of symmetric SCs. For instance, aqueous symmetric systems have the ability to operate at a limited voltage of only $1.2 \mathrm{~V}$, whereas asymmetric SCs can operate at a potential window of more than $2.0 \mathrm{~V}$ (Wang et al., 2013).

In this respect, Lu et al. (2013) reported the synthesis of porous VN nanowire anodes for a quasi-solid-state asymmetric super capacitor (ASC) device that had a high energy density based on a $\mathrm{VO}_{\mathrm{X}}$ nanowire cathode. The $\mathrm{VO}_{\mathrm{x}} / \mathrm{VN}$-ASC device was shown to have a very stable electrochemical window of $1.8 \mathrm{~V}$ and an outstanding cyclic stability with a $12.5 \%$ decrease of capacitance after 10,000 cycles. Moreover, the $\mathrm{VO}_{\mathrm{x}} / \mathrm{VN}$-ASC device exhibited a high energy density of $0.61 \mathrm{mWh} \mathrm{cm}^{-3}$ with a current density of $0.5 \mathrm{~mA} \mathrm{~cm}^{-2}$, having a power density of $0.85 \mathrm{~W} \mathrm{~cm}^{-3}$ at a current density of $5 \mathrm{~mA} \mathrm{~cm}^{-2}$.

With this view, Venkateshalu and Grace (2020) fabricated asymmetric cells by using $\mathrm{Ti}_{3} \mathrm{C}_{2} \mathrm{Tx}$ MXene as a negative electrode and vanadium nitride/Porous carbon (VN/PC) as a positive electrode. VN/PC was chosen because of its various oxidation states which helps in creating greater charge-discharge rates. Many groups have reported on carbon composites with vanadium nitrides as the SCs electrode (Ghimbeu et al., 2011; Balamurugan et al., 2016a; Liu Y. et al., 2016). This composite showed a wider potential window $(1.8 \mathrm{~V})$ when compared to published reports (Li et al., 2017; Jiang et al., 2018; Pan et al., 2019). The specific capacitance for VN/PC electrode was 52 $\mathrm{F} / \mathrm{g}$ at $0.5 \mathrm{~A} / \mathrm{g}$ by using $6 \mathrm{M} \mathrm{KOH}$. However, VN/PC// $\mathrm{Ti}_{3} \mathrm{C}_{2} \mathrm{Tx}$ asymmetric cells showed a specific capacitance of $105 \mathrm{~F} / \mathrm{g}$ at $1 \mathrm{~A} / \mathrm{g}$ by using the same electrolyte with an energy density and power density of $12.81 \mathrm{Wh} / \mathrm{kg}$ and $985.8 \mathrm{~W} / \mathrm{kg}$ because of the superior electrical conductivity and electrochemical stability of $\mathrm{Ti}_{3} \mathrm{C}_{2} \mathrm{Tx}$.

In a recent development, it was seen that $\mathrm{VN}$ has a high hydrogen evolution potential, hence having the ability to exhibit a greater potential window that could act as an anode for ASCs (Su and Zhitomirsky, 2014; Yuan et al., 2019b). But in aqueous electrolytes VN shows an electrochemical instability (Choi and Kumta, 2005; Glushenkov et al., 2010; Zhang et al., 2011).

Zhang et al. (2017) fabricated carbon encapsulated vanadium nitride nanowires (NWs) for application SCs that showed a greater capacitance and cycling stability. In this regard, Jia et al. (2020) fabricated 3D structured VN microsheets shelled with a nitrogen doped layer of carbon (VN@NC) for its application in ASCs by using melamine as a source of nitrogen. They used $\mathrm{NiCo}_{2} \mathrm{O}_{4}$ nanowire as a cathode and VN@NC as an anode and $\mathrm{PVA} / \mathrm{KOH}$ gel as a solid electrolyte. This as-synthesized electrode displayed a high capacitance of $368 \mathrm{~F} / \mathrm{g}$. The asymmetric device exhibited a high energy density of $65.3 \mathrm{Wh} / \mathrm{kg}$ at $800 \mathrm{~W} / \mathrm{kg}$. Furthermore, this ASC shows an ultra-stable performance while bending from $0^{\circ}$ to $180^{\circ}$. This development can be used to provide many new potential strategies for the fabrication of anode materials.

TABLE 1 | Capacitance of reported metal nitride composites.

\begin{tabular}{|c|c|c|c|c|c|}
\hline Materials & Specific capacitance & Scan rate & Cyclic stability & Capacity retention & References \\
\hline TiN/NN & $170 \mathrm{~F} / \mathrm{g}$ & $2 \mathrm{mV} / \mathrm{s}$ & 500 & $89 \%$ & Lu et al., 2012 \\
\hline TiVN & $15 \mathrm{mF} / \mathrm{cm}^{2}$ & $2 \mathrm{mV} / \mathrm{s}$ & 10,000 & $99 \%$ & Achour et al., 2017 \\
\hline $\mathrm{CrN}$ & $31.3 \mathrm{mF} / \mathrm{g}$ & $1 \mathrm{mV} / \mathrm{s}$ & 20,000 & $94 \%$ & Wei et al., 2018 \\
\hline $\mathrm{NbN}$ & $707.1 \mathrm{~F} / \mathrm{cm}^{3}$ & $2 \mathrm{mV} / \mathrm{s}$ & 20,000 & $92.9 \%$ & Shen et al., 2018 \\
\hline $\mathrm{HfN}$ & $5.6 \mathrm{~m} / \mathrm{F}^{2}$ & $10 \mathrm{mV} / \mathrm{s}$ & 4,000 & $91.2 \%$ & Gao X. et al., 2019 \\
\hline 2D VN/carbon sheet & $249 \mathrm{~F} / \mathrm{g}$ & $5 \mathrm{mV} / \mathrm{s}$ & 5,000 & $75.8 \%$ & Wu et al., 2019 \\
\hline $\mathrm{Mo}_{2} \mathrm{~N} / \mathrm{PANI}$ & $111.8 \mathrm{~F} / \mathrm{g}$ & $30 \mathrm{mV} / \mathrm{s}$ & - & $66.5 \%$ & He et al., 2020 \\
\hline $\mathrm{TiN} @ \mathrm{MnO}_{2}$ & $386 \mathrm{~F} / \mathrm{g}$ & $10 \mathrm{mV} / \mathrm{s}$ & 4,000 & $111.7 \%$ & Xu et al., 2019 \\
\hline
\end{tabular}


There is now evidence that VN NWs are comparable in their activity; this opens up fresh avenues for nitride researchers.

Similarly, Zhou et al. (2020) synthesized N-doped carbon skeleton@vanadium nitrogen (CTF/N-C@VN) using the solvothermal method. They assembled an all-in-one supercapacitor by matching a CTF/N-C@VN anode and Ndoped carbon skeleton@manganese dioxide (CTF/N-C @ $\mathrm{MnO}_{2}$ ) cathode in an internal asymmetric fashion. This all-in-one SC showed a high specific capacitance of $336.7 \mathrm{mF} / \mathrm{cm}^{2}$ and a greater energy density of $2032.8 \mu \mathrm{Wh} / \mathrm{cm}^{2}$. This work showed a scalable route to develop ultrahigh energy density SCs for the development of next generation portable and wearable electronics. Table 2 lists the Specific capacitance and current density values of some metal nitrides for ASC.

Therefore, it can be concluded that the superior properties of metal nitrides, such as their thermodynamic stability, chemical, and mechanical properties, have made them potentially useful to many technologies, such as SCs. Their surface stability in particular may provide avenues that metal oxides can't.

\section{Lithium-Ion Batteries (LIBs)}

Rechargeable lithium-ion batteries (LIBs) are considered to be the most potent energy storage system for many applications, including electric vehicles and electronic devices, because of their high gravimetric and volumetric energy, long cycle life, low selfdischarge properties, and high power density (Kang et al., 2006). Increased interest is being paid to metal nitrides because of their remarkable electrochemical properties, standard technological approach, high chemical stability, and extensive fundamental importance (Dong et al., 2013; Balogun et al., 2014, 2015; Nandi et al., 2014).

In this regard, Lai et al. (2014) synthesized $\mathrm{Fe}_{2} \mathrm{~N}$ that was used as a binder-free anode in lithium ion batteries' half-cell. It was seen that an outstanding electrochemical performance was achieved with a high reversible capacity of $900 \mathrm{mAh} / \mathrm{g}$, having a capacity retention of $76 \%$ at $600 \mathrm{~mA} / \mathrm{g}$ after 300 cycles. After 50 cycles $\mathrm{Fe}_{2} \mathrm{~N}$ nanoparticles (NPs) showed a capacity of $243 \mathrm{mAh} / \mathrm{g}$, when current density was slowly increased from 1,000 to 6,000 $\mathrm{mA} / \mathrm{g}$. A remarkable performance of $\mathrm{Fe}_{2} \mathrm{~N}$ occurred because of combining both a nanostructured and flexible free-standing binder-free approach in the cell set-up. Moreover, a flexible LIB device with a higher power density and energy density based on $\mathrm{Fe}_{2} \mathrm{~N}$ nanoparticles (NPs) and a $\mathrm{LiCoO}_{2}$ positive electrode was also demonstrated. $\mathrm{Fe}_{2} \mathrm{~N} / \mathrm{LiCoO}_{2}$ not only achieved a high energy density of $688 \mathrm{Wh} / \mathrm{kg}$ at a current density of $200 \mathrm{~mA} / \mathrm{g}$ and high power density of $3,200 \mathrm{~W} / \mathrm{kg}$ at a current density of $1,000 \mathrm{~mA} / \mathrm{g}$, but also showed outstanding flexibility and a good electrochemical performance.
Similarly, another anode material was reported by Zhang B. et al. (2014) for use in LIBs in 2014. The MoN/GNS hybrid materials were reported to exhibit a larger reversible capacity, outstanding cycling performance, and rate capability as an anode material for LIBs.

Kundu et al. (2015) reported another method for the synthesis of $\mathrm{VN}$, nanocrystalline form, and its carbon coated analog as an electrode (anode) material for LIBs. It is reported that VN nanomaterials show the insertion/extraction of $\mathrm{Li}^{+}$ions from empty lattice sites face-centered-cubic VN. This maintains a durable capacity of $400 \mathrm{mAhg}^{-1}$ that is equal to the reaction of $\sim 1 \mathrm{Li}$ per $\mathrm{VN}$ unit. The process of insertion increases the rate capability of the material. At $\mathrm{C} / 5$ current density, theoretical specific capacity is delivered which is dropped by $14 \%$ at $\mathrm{C} / 3$ rate. At $1 \mathrm{C}$ rate a $200 \mathrm{mAhg}^{-1}$ durable capacity is achieved.

In 2017, Huang et al. (2017) reported on $\mathrm{Fe}_{3} \mathrm{~N}$ as an anode material for LIBs that was constrained inside carbon nanocages. It was seen that $\mathrm{Fe}_{3} \mathrm{~N} @ \mathrm{C}$ nanoparticles in a long-term cyclic charging/discharging process shows a high electric capacity. The electrochemical lithiation/delithiation reactivity of the $\mathrm{Fe}_{3} \mathrm{~N}$ core maintains its outstanding performance and the constraint of the carbon shell helps to maintain the stable nanostructure of the electrodes sustained in long cycles.

Similarly, Zou et al. (2018) reported the synthesis of NiCoN@C-NCNT nanocomposites and their applications for LIBs. In situ TEM observations showed that some of the $\mathrm{NiCo}_{2} \mathrm{~N}$ nanoparticles are spread along the surface of NCNTs and enter NCNTs to defend themselves, enabling them to show the outstanding cycling stability of composite electrodes. This composite provides good electron and ion-transport capability. A remarkable lithium storage performance, which also includes excellent cycling stability, high specific capacity, and outstanding rate performance, was shown by NiCoN@C-NCNT nanocomposite electrodes. It is reported that a $624.5 \mathrm{mAhg}^{-1}$ reversible capacity was obtained at $2,000 \mathrm{mAg}^{-1}$ current density and retained at $569.1 \mathrm{mAhg}^{-1}$ after 500 cycles.

Figure 11A demonstrates the CV curves of the NiCoN@CNCNT nanocomposite at a scan rate of $0.1 \mathrm{mV} \mathrm{s}^{-1}$ and Figure 11B shows the charge/discharge curves of the NiCoN@CNCNT nanocomposite. Figure 11C demonstrates the rate performance of the NiCoN@C-NCNT nanocomposite. Figure 11D exhibits the cycling performance and consequent column efficiency of the NiCoN@C-NCNT nanocomposite. Figure 11E shows the cycling performance of NiCoN@C-NCNT and $\mathrm{NiCoO}_{4}-\mathrm{CNT}$.

Sun et al. (2017) synthesized gallium nitride (GaN) nanosheets (NSs) using the graphene oxide templating method as an anode material for LIBs. The atomic force microscopy revealed that the

TABLE 2 | Specific capacitance and current density values of some metal nitrides for ASC.

\begin{tabular}{|c|c|c|c|c|c|}
\hline Materials & Specific capacitance & Current density & Potential window & Electrolyte & References \\
\hline $\mathrm{VN} / \mathrm{PC} / / \mathrm{Ti}_{3} \mathrm{C}_{2} \mathrm{Tx}$ & 105 F/g & $1 \mathrm{~A} / \mathrm{g}$ & $1.8 \mathrm{~V}$ & $6 \mathrm{M} \mathrm{KOH}$ & Venkateshalu and Grace, 2020 \\
\hline NV@NC & $368 \mathrm{~F} / \mathrm{g}$ & $1 \mathrm{~A} / \mathrm{g}$ & $-1.0-0.0 \mathrm{~V}$ & $\mathrm{PVA} / \mathrm{KOH}$ & Jia et al., 2020 \\
\hline CTF/N-C@VN & $336.7 \mathrm{mF} / \mathrm{cm}^{2}$ & $1.5 \mathrm{~A} / \mathrm{g}$ & $0.0-1.0 \mathrm{~V}$ & PVA gel & Zhou et al., 2020 \\
\hline
\end{tabular}




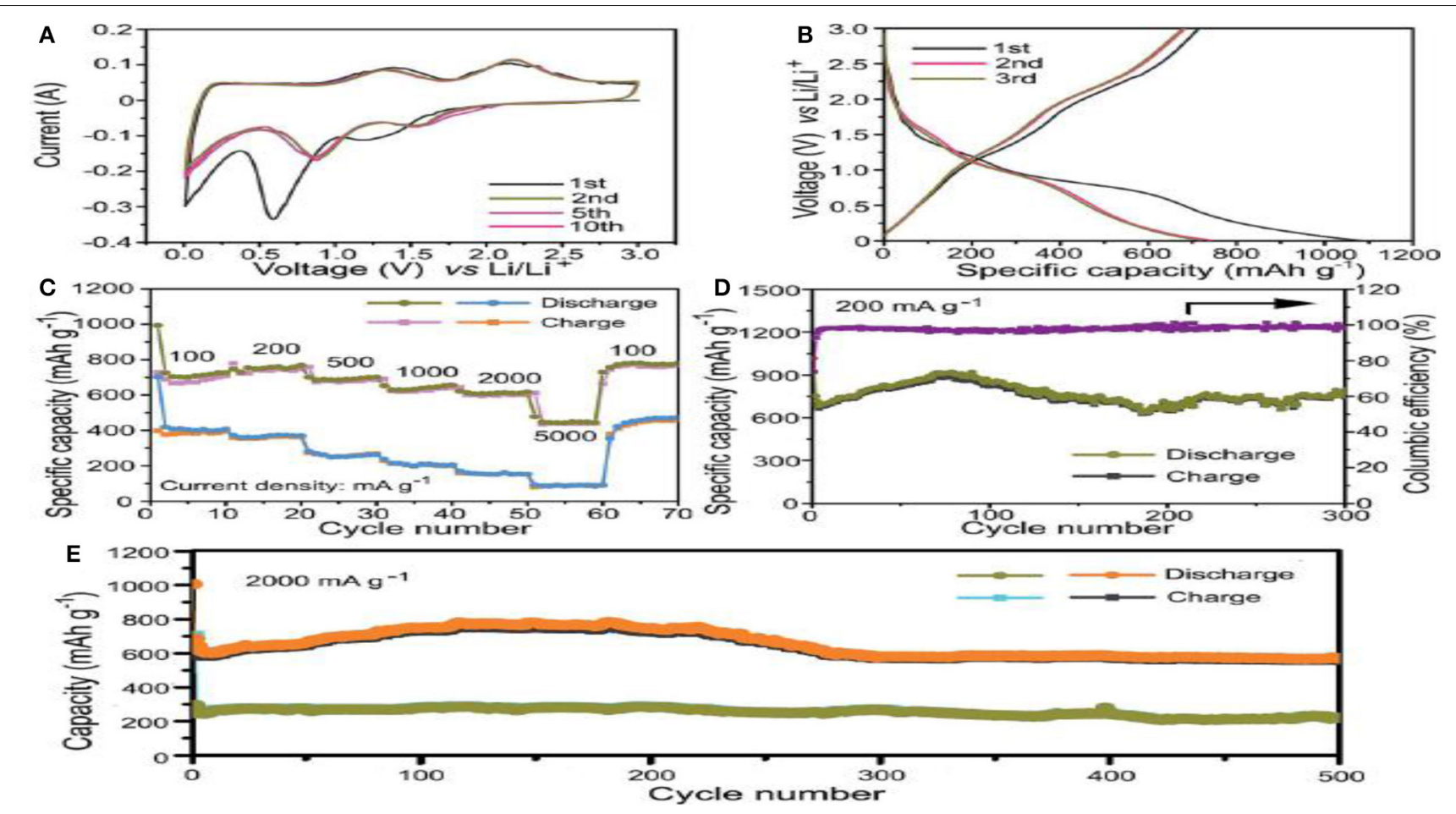

FIGURE 11 | (A) CV curves of the NiCoN@C-NCNT nanocomposite at a scan rate of $0.1 \mathrm{mV} \mathrm{s}^{-1}$ between 0.01 and $3 \mathrm{~V} 14$ (B) Charge/discharge curves of the NiCoN@C-NCNT nanocomposite at constant current density of $100 \mathrm{~mA} \mathrm{~g}^{-1} .11$ (C) Rate performance of the NiCoN@C-NCNT nanocomposite at different current densities. 11 (D) Cycling performance and consequent columbic efficiency of the NiCoN@C-NCNT nanocomposite at $200 \mathrm{~mA} \mathrm{~g}^{-1}$ current density. 11 (E)

NiCoN@C-NCNT cycling performance and $\mathrm{NiCoO}_{4}$-CNT nanocomposite measured at the high current density of 2,000 mA g ${ }^{-1}$ [Reproduced from Zou et al. (2018) with permission from Royal Society of Chemistry].

height of GaN NS was $14.5 \mathrm{~nm}$ in thickness and $3 \mu \mathrm{m}$ in size. This as-synthesized electrode material delivers a discharge capacity up to $702 \mathrm{~mA} \mathrm{h/g}$ after 100 cycles at $1 \mathrm{~A} / \mathrm{g}$ and above $600 \mathrm{~mA}$ h/g after 1,000 cycles at $1 \mathrm{~A} / \mathrm{g}$. This newly synthesized GaN NS displayed an ultrahigh rate capability.

Cation deficient nanomaterials have been found to be feasible as an electrode material in electrochemical energy storage, especially 1D NWs. Considering this, Sun et al. (2020) synthesized cation deficient GaN nanowires (NWs) using CVD with a plasma treatment. This cation deficient GaN enhanced electrochemical performance by increasing electrical conductivity and charge transfer. When this GaN NWs were tested as an anode material, it was seen that this material displays higher capacities of $746.5 \mathrm{mAh} / \mathrm{g}$ at $0.1 \mathrm{~A} / \mathrm{g}$ after 100 cycles and $370.2 \mathrm{mAh} / \mathrm{g}$ at $10 \mathrm{~A} / \mathrm{g}$ after 1,000 cycles, when compared to pristine $\mathrm{GaN}$ nanowires. This showed that the presence of gallium defects at the electrode enhances the lithiation/delithiation process. DFT calculations proved that the $1 \mathrm{D}$ nanostructure and cation defects can increase electrical conductivity and enhance charge transfer to boost lithium-ion storage for lithium ion batteries.

Jiang et al. (2019) synthesized a 3D ordered, bicontinuous cubic, and conductive framework of cobalt nitride $(\mathrm{CoN})$ and used this as an anode material for LIBs. This 3D grid-like mesoporous structure of $\mathrm{CoN}$ with a conductive skeleton permits enhanced lithium ion $\left(\mathrm{Li}^{+}\right)$permeability and smooth electron transfer at a faster rate. This $3 \mathrm{D}$ structured CoN delivers a large capacity, an increased rate capability, and a specific capacity of $710 \mathrm{~mA} \mathrm{hg}{ }^{-1}$ after 350 cycles at $1 \mathrm{~A} / \mathrm{g}$. Results showed that 3D ordered mesoporous cobalt nitride is good for fast-kinetics and stable-cycling lithium storage.

Lithium sulfur (Li-S) batteries are one of the most potent alternative electrochemical systems because of their higher theoretical specific capacity and higher theoretical energy density. Niobium nitride $(\mathrm{NbN})$ has a greater electrical conductivity and good chemical stability, so can be used for this application. In this regard, Shi et al. (2020) synthesized NbN nanoparticles with in-situ growth on the surface of graphene through the polyol-mediated solvothermal reaction. Li-S batteries with NbN/G exhibit better cyclability with a residual capacity of $768 \mathrm{mAh} / \mathrm{g}$ after 300 cycles at $1 \mathrm{C}$ with a low capacity decay $0.096 \%$ at an increased rate performance of $937 \mathrm{mAh} / \mathrm{g}$ at $2 \mathrm{C}$. Furthermore, it was seen that through a coupling with sulfur/carbon nanofiber cathode, an ultrahigh areal capacity of $12.5 \mathrm{mAhcm}^{-2}$ can be achieved. These remarkable results occurred because polar $\mathrm{NbN}$ not only acts as a chemical reservoir to adsorb diffused lithium polysulfide (LiPs) but increases the redox reaction of LiPs as well. Similarly, the good dispersibility and small size of $\mathrm{NbN}$ particles forms greater electroactive sites for interaction with LiPs, and 
the close contact between $\mathrm{NbN}$ and graphene facilitates fast electron transport.

Similarly, Gao X. et al. (2019) reported on the structure by employing highly ordered mesoporous carbon (OMC) as a matrix and surface oxidized quantum dot size titanium nitride (TiN-O) as a polysulfide to boost redox kinetics. Because of the polar surface of TiN, this composite chemically immobilizes LiPs. Using DFT studies, it was proven that a strong charge polarization effect for polysulfides was rendered by TiN-O containing surface oxygen by S-O-Ti bond. Both a suppressed shuttle effect and a high lithium ion diffusion coefficient causes an increase in capacity $(1,264 \mathrm{mAh} / \mathrm{g})$ at $0.2 \mathrm{C}$ with $0.06 \%$ fading rate per cycle. This TiN-O-OMC electrode shows enhancement on $\mathrm{Li}_{2} \mathrm{~S}$ nucleation/deposition conversion, a lower polarization of $271 \mathrm{mV}$, and an increase in the charge transfer process. This electrode displayed high specific capacities at $0.1 \mathrm{C}$ $(1,395 \mathrm{mAh} / \mathrm{g})$ and $5 \mathrm{C}(726 \mathrm{mAh} / \mathrm{g})$ with higher coulombic efficiencies (100\%). For prototype pouch cells, this cathode material exhibited a high capacity $(890 \mathrm{~mA} / \mathrm{g})$ at $0.2 \mathrm{C}$ and stable cycling performance $(634 \mathrm{~mA} / \mathrm{g})$ after 120 cycles.

Wang et al. (2019) synthesized MoN-nitrogen doped carbon using the template free hydrothermal process.MoN@NC has the ability to enhance electrical conductivity and facilitates electron transfer process as well as kinetics of ion diffusion. At $0.2 \mathrm{~A} / \mathrm{g}$ current density, this anode material displayed a capacity of 760 $\mathrm{mAh} / \mathrm{g}$ after 200 cycles, and an initial discharge capacity of 873 $\mathrm{mAh} / \mathrm{g}$ with a $61.2 \%$ columbic efficiency. For rate capabilities, a higher capacity of $640 \mathrm{mAh} / \mathrm{g}$ was observed at $0.1 \mathrm{~A} / \mathrm{g}$ and at 0.5 $\mathrm{A} / \mathrm{g}$ current density, a higher capacity of $720 \mathrm{mAh} / \mathrm{g}$ was delivered after 60 cycles which displayed a good rate reversibility. In terms of long cycling performance, this electrode material displayed a higher capacity of $571 \mathrm{mAh} / \mathrm{g}$ at $1 \mathrm{~A} / \mathrm{g}$ current density after 800 cycles with a capacity retention over $100 \%$. This showed that MoN@NC has potential for use in LIBs.

\section{Sodium-Ion Batteries (NIBs)}

Furthermore, it is of interest to note that metal nitrides have shown desirable performance in sodium-ion batteries.

Liu S.-L. et al. (2016) reported on $\mathrm{Mo}_{2} \mathrm{~N}$ as an anode material for sodium-ion batteries. Their results exhibited that porous $\mathrm{Mo}_{2} \mathrm{~N}$ nanobelts showed excellent cyclability, remarkable reversible capacity, and high capacity retention rates of $85 \%$ over 200 cycles. Chen et al. (2017) synthesized $2 \mathrm{D} \mathrm{Ca}_{2} \mathrm{~N}$ and found its application as an electrode material in NIBs. It is reported that an initial discharge capacity of $1110.5 \mathrm{mAh} \mathrm{g}^{-1}$ at $50 \mathrm{~mA} \mathrm{~g}^{-1}$ between 0 and $3 \mathrm{~V}$ was achieved, that remains $327 \mathrm{mAh} \mathrm{g}^{-1}$ after 30 cycles.

Moreover, Yuan et al. (2019a) reported on the synthesis of vanadium nitride nanohybrids quantum dots that were implanted within porous shells of $\mathrm{N}$-doped carbon hollow spheres (VNQD@NC HSs). They investigated that this type of nanohybrid can be used as an anode material for SIBs. It facilitates transfer for electrons as well as $\mathrm{Na}^{+}$. The VNQD@NC HSs electrode retards capacities of up to $361 \mathrm{mAhg}^{-1}$ at a current density of $0.1 \mathrm{Ag}^{-1}$ after 200 cycles and delivers reversible capacity of $306 \mathrm{mAh} \mathrm{g}^{-1}$ at $1 \mathrm{Ag}^{-1}$ over 1,400 cycles.

\section{Fuel Cell Application}

$\mathrm{Wu}$ and Chen (2011) synthesized cubic copper nitride $\left(\mathrm{Cu}_{3} \mathrm{~N}\right)$ nanocrystals. They reported that in electrochemical studies, assynthesized $\mathrm{Cu}_{3} \mathrm{~N}$ nanocubes showed excellent electrocatalytic activity toward oxygen reduction. Such nanocrystals were found to be a potent candidate to act as cathodic electrocatalysts in alkaline fuel cells.

Seifitokaldani and Savadogo (2015) prepared titanium oxynitride (TiON) using the sol-gel method for platinumbased electrocatalysts in polymer electrolyte membrane (PEM) fuel cells applications. TiON have shown a much higher stability under high oxidation potential conditions. A Pt/TiON electrocatalyst showed a higher active surface area than $\mathrm{Pt} / \mathrm{C}$ electrocatalyst.

Tian et al. (2018) reported on the synthesis of hierarchical binary titanium-based nitrides $\left(\mathrm{Ti}_{0.8} \mathrm{Co}_{0.2} \mathrm{~N}\right)$ for fuel cell applications. This oxygen electrocatalyst showed its application both in alkaline zinc-air fuel cells and hydrogen-air, exhibiting high power density and stability especially for alkaline $\mathrm{Zn}$-air fuel cells. Doping of Co in titanium, modifies the electronic structure, which increased the intrinsic activity of titanium nitrides for oxygen reduction.

Hence, metal nitrides may be used for fuel cell application because of their greater stability, surface chemistry stability, corrosion resistance, and enhanced mass transport properties.

In general, the above-mentioned results showed that metal nitrides have various applications in several emerging fields such as SCs, fuel cells, LIBs, solar cells, etc. The scalability of synthetic protocols and device relevant properties are considered to be an important research area which requires proper attention in the future. Hence, through ongoing multi-disciplinary work in the field of nitrides, we can expect many new investigations to come in time.

\section{CONCLUSION AND FUTURE OUTLOOKS}

In this focus review, synthetic routes of nitrides and their energy applications are presented. Nanosized metal nitrides are versatile for use in multifunctional platforms. It is predictable that many more applications are likely to be achieved in the future, especially in energy platforms.

Many synthetic strategies have been developed to produce metal nitrides. For the synthesis of nitrides, the main route is ammonia reduction annealing. The hydrothermal method is the most commonly used as many metal nitrides can be synthesized with different morphologies according to heating time, however for synthesis of metal nitride films this method is not suitable because film thickness obtained is not so uniform. For this purpose, the sputtering method is mostly used as the thickness of the prepared film is uniform but its capacitance may be low because of its compactness. Similarly, the salt template method can be used to obtain metal nitrides with different shapes. Electrospinning is useful to obtain electrodes with special morphologies through the adjustment of current parameters. At present, most metal nitrides are synthesized by the hydrothermal method or solid state method of synthesis. TiN is the most 
studied example of metal nitrides. In SCs, composites of titanium and vanadium nitride have shown excellent results because of their good electrical conductivity and enhanced charge transfer rate. TiN@ $\mathrm{MnO}_{2}$ and VN/C have shown excellent results with specific capacitances of 386 and $249 \mathrm{~F} / \mathrm{g}$ having capacities of 111.7 and $75.8 \%$ capacity retention after 4,000 and 5,000 cycles. In LIBs, cation deficient $\mathrm{GaN}$ nanowires have shown higher capacities of $746.5 \mathrm{mAh} / \mathrm{g}$, indicating that many other metal nitrides that have cation defects can be proved helpful to boost lithium ion storage in LIBs for future use. Furthermore, TiN-O-OMC displayed excellent specific capacitance $(1,395 \mathrm{mAh} / \mathrm{g})$; this showed that the surface oxidation of metals can be helpful for LIBs. Metal nitrides show attractive high-rate capabilities for EES devices and also enhanced catalytic reactivity for fuel cells, as they are highly conductive in nature and show good reactivity. Nanostructured metal nitrides generally show better performance than bulk materials because of their decreased particle size and higher surface area. Some metal nitrides started to decompose during the process of cycling as they are unstable in aqueous electrolyte. So, in order to prevent decomposition, coating of metal nitrides must be achieved by some protective layers. This will improve cycling life and reactivity; some additional investigations are also needed to design some analogous techniques to realize the full breadth of available chemical properties and optical responses of these materials.

Nanostructured metal nitrides still deserve further exploration because of their unique physical, chemical, and electrochemical properties. Furthermore, in-situ characterization techniques require better study, to improve the understanding of synthesized nanomaterials and the mechanisms of reaction, as well as find new methods of lithium/sodium storage and reaction pathways. Moreover, highly reproducible and cost-effective

\section{REFERENCES}

Achour, A., Lucio-Porto, R., Chaker, M., Arman, A., Ahmadpourian, A., Soussou, M., et al. (2017). Titanium vanadium nitride electrode for micro-supercapacitors. Electrochem. Commun. 77, 40-43. doi: 10.1016/j.elecom.2017.02.011

Achour, A., Porto, R. L., Soussou, M.-A., Islam, M., Boujtita, M., Aissa, K. A., et al. (2015). Titanium nitride films for microsupercapacitors: effect of surface chemistry and film morphology on the capacitance. J. Power Sources 300, 525-532. doi: 10.1016/j.jpowsour.201 5.09.012

Alexander, A.-M., and Hargreaves, J. S. (2010). Alternative catalytic materials: carbides, nitrides, phosphides and amorphous boron alloys. Chem. Soc. Rev. 39, 4388-4401. doi: 10.1039/b916787k

Alpen, U. V., Rabenau, A., and Talat, G. (1977). Ionic conductivity in $\mathrm{Li}_{3} \mathrm{~N}$ single crystals. Appl. Phys. Lett. 30, 621-623. doi: 10.1063/1.89283

Anasori, B., Lukatskaya, M. R., and Gogotsi, Y. (2017). 2d metal carbides and nitrides (mxenes) for energy storage. Nat. Rev. Mater. 2:16098. doi: 10.1038/natrevmats.2016.98

Andrievski, R. (1997). Films of interstitial phases: synthesis and properties. J. Mater. Sci. 32, 4463-4484. doi: 10.1023/A:10186048 30327

Arico, A. S., Bruce, P., Scrosati, B., Tarascon, J.-M., and Van Schalkwijk, W. (2011). "Nanostructured materials for advanced energy conversion and storage devices," in Materials for Sustainable Energy: A Collection of PeerReviewed Research and Review Articles From Nature Publishing Group, ed V. methods of synthesis are more favorable to obtain metal nitrides showing outstanding performances. Future studies should focus on tuning synthesis for monodispersed metal nitride NPs and field flow fractionation to separate NPs of different sizes. Synthesis of TiN MXene is reported by wet chemical etching method, but this is hazardous for the environment as it requires strong acids $(\mathrm{HF}, \mathrm{HCl}$, and $\mathrm{HNO}_{3}$ ), hence the hydrothermal method can be used for the synthesis of nitride MXene in future. Design and production of advanced flexible metal nitride-based electrodes required for LIBs/SIBs is essential for the investigation of electronics. As it is an interdisciplinary topic, it requires the cooperation of researchers with expertise in several fields. Development of synthetic methodologies for metal nitride synthesis presents opportunities for future investigations, including study into broadening material properties such as size, shape, and surface protection functionalization, of materials. Further development of sustainable and clean electrode materials with novel compositions that are environmentally friendly is needed. Moreover, electrode materials for different electrochemical applications should be selected by computer simulation and optimization of different experimental parameters. For SCs, the development of asymmetrical hybrid SCs can be used as an effective and efficient way to meet market demands for energy density of SCs.

\section{AUTHOR CONTRIBUTIONS}

IA compiled the manuscript and dug the whole literature. MI guided to write manuscript and critically reviewed the whole manuscript. SR helped in writing manuscript. All authors contributed to the article and approved the submitted version.
Dusastre (Nature Publishing Group), 148-159. Available online at: https:// www.worldscientific.com/author/Dusastre\%2C+Vincent

Balamurugan, J., Karthikeyan, G., Thanh, T. D., Kim, N. H., and Lee, J. H. (2016a). Facile synthesis of vanadium nitride/nitrogen-doped graphene composite as stable high performance anode materials for supercapacitors. J. Power Sources 308, 149-157. doi: 10.1016/j.jpowsour.2016.01.071

Balamurugan, J., Thanh, T. D., Kim, N. H., and Lee, J. H. (2016b). Nitrogen-doped graphene nanosheets with fen core-shell nanoparticles as high-performance counter electrode materials for dye-sensitized solar cells. Adv. Mater. Interfaces 3:1500348. doi: 10.1002/admi.201500348

Balogun, M.-S., Qiu, W., Wang, W., Fang, P., Lu, X., and Tong, Y. (2015). Recent advances in metal nitrides as high-performance electrode materials for energy storage devices. J. Mater. Chem. A 3, 1364-1387. doi: 10.1039/C4TA05565A

Balogun, M.-S., Yu, M., Li, C., Zhai, T., Liu, Y., Lu, X., et al. (2014). Facile synthesis of titanium nitride nanowires on carbon fabric for flexible and high-rate lithium ion batteries. J. Mater. Chem. A 2, 10825-10829. doi: 10.1039/C4TA00987H

Balogun, M.-S., Zeng, Y., Qiu, W., Luo, Y., Onasanya, A., Olaniyi, T. K., et al. (2016). Three-dimensional nickel nitride $\left(\mathrm{Ni}_{3} \mathrm{~N}\right)$ nanosheets: free standing and flexible electrodes for lithium ion batteries and supercapacitors. J. Mater. Chem. A 4, 9844-9849. doi: 10.1039/C6TA02492K

Banakh, O., Schmid, P., Sanjines, R., and Levy, F. (2003). Hightemperature oxidation resistance of crl- xalxn thin films deposited by reactive magnetron sputtering. Surf. Coat. Technol. 163, 57-61. doi: 10.1016/S0257-8972(02)00589-3

Buha, J., Djerdj, I., Antonietti, M., and Niederberger, M. (2007). Thermal transformation of metal oxide nanoparticles into nanocrystalline metal nitrides 
using cyanamide and urea as nitrogen source. Chem. Mater. 19, 3499-3505. doi: $10.1021 / \mathrm{cm} 0701759$

Cao, J., Li, T., Gao, H., Lin, Y., Wang, X., Wang, H., et al. (2020). Realization of 2d crystalline metal nitrides via selective atomic substitution. Sci. Adv. 6:eaax8784. doi: $10.1126 /$ sciadv.aax 8784

Chang, Y.-H., Chiu, C.-W., Chen, Y.-C., Wu, C.-C., Tsai, C.-P., Wang, J.-L., et al. (2002). Syntheses of nano-sized cubic phase early transition metal carbides from metal chlorides and n-butyllithium. J. Mater. Chem. 12, 2189-2191. doi: $10.1039 / \mathrm{b} 203927 \mathrm{c}$

Chen, G., Bai, Y., Li, H., Li, Y., Wang, Z., Ni, Q., et al. (2017). Multilayered electride $\mathrm{Ca}_{2} \mathrm{~N}$ electrode via compression molding fabrication for sodium ion batteries. ACS Appl. Mater. Interfaces 9, 6666-6669. doi: 10.1021/acsami.6b16186

Chen, H., Wang, L., Bai, J., Hanson, J. C., Warren, J. B., Muckerman, J. T., et al. (2010). In situ xrd studies of $\mathrm{Zno} / \mathrm{GaN}$ mixtures at high pressure and high temperature: synthesis of $\mathrm{Zn}$-rich $\left(\mathrm{Ga} 1-_{\mathrm{x}} \mathrm{Zn}_{\mathrm{x}}\right)\left(\mathrm{N} 1-{ }_{\mathrm{x}} \mathrm{O}_{\mathrm{x}}\right)$ photocatalysts. J. Phys. Chem. C.114, 1809-1814. doi: 10.1021/jp909649n

Chen, L.-F., Zhang, X.-D., Liang, H.-W., Kong, M., Guan, Q.-F., Chen, P., et al. (2012). Synthesis of nitrogen-doped porous carbon nanofibers as an efficient electrode material for supercapacitors. ACS Nano 6, 7092-7102. doi: $10.1021 / \mathrm{nn} 302147 \mathrm{~s}$

Cheng, D., Xia, H., and Chan, H. S. O. (2006). Fabrication of polymeric hollow nanospheres, hollow nanocubes and hollow plates. Nanotechnology 17, 1661-1667. doi: 10.1088/0957-4484/17/6/021

Choi, D., and Kumta, P. N. (2005). Chemically synthesized nanostructured vn for pseudocapacitor application. Electrochem. Solid. St. 8:A418. doi: 10.1149/1.1951201

Cui, Z., Yang, M., and DiSalvo, F. J. (2014). Mesoporous $\mathrm{Ti}_{0.5} \mathrm{Cr}_{0.5} \mathrm{~N}$ supported pdag nanoalloy as highly active and stable catalysts for the electro-oxidation of formic acid and methanol. ACS Nano 8, 6106-6113. doi: 10.1021/nn5014337

Das, B., Behm, M., Lindbergh, G., Reddy, M., and Chowdari, B. (2015). High performance metal nitrides, $\mathrm{mn}(\mathrm{m}=\mathrm{cr}$, co) nanoparticles for non-aqueous hybrid supercapacitors. Adv. Powder Technol. 26, 783-788. doi: 10.1016/j.apt.2015.02.001

Didziulis, S. V., Butcher, K. D., and Perry, S. S. (2003). Small cluster models of the surface electronic structure and bonding properties of titanium carbide, vanadium carbide, and titanium nitride. Inorg. Chem. 42, 7766-7781. doi: $10.1021 / \mathrm{ic} 030140 \mathrm{k}$

Ding, J., Deng, C., Yuan, W., Zhu, H., and Li, J. (2013). The synthesis of titanium nitride whiskers on the surface of graphite by molten salt media. Ceram. Int. 39, 2995-3000. doi: 10.1016/j.ceramint.2012.09.077

Ding, J., Deng, C., Yuan, W., Zhu, H., and Zhang, X. (2014a). Novel synthesis and characterization of silicon carbide nanowires on graphite flakes. Ceram. Int. 40, 4001-4007. doi: 10.1016/j.ceramint.2013.08.051

Ding, J., Deng, C., Zhu, H., Zhang, X., and Guo, D. (2014b). Novel preparation of a porous composite insulating scaffold from forsterite and sodium carbonate media. Int. J. Mater. Res. 105, 1140-1144. doi: 10.3139/146.111117

Ding, J., Zhu, H., Deng, C., Li, G., Wang, K., and Liu, J. (2015). Preparation and characterisation of porous biomorphic sic/c ceramic from molten salt. Ceram. Int. 41, 11539-11545. doi: 10.1016/j.ceramint.2015.05.080

Ding, J., Zhu, H., Li, G., Deng, C., and Chai, Z. (2016). Catalyst-assisted synthesis of $\alpha-\mathrm{Si}_{3} \mathrm{~N}_{4}$ in molten salt. Ceram. Int. 42, 2892-2898. doi: 10.1016/j.ceramint.2015.10.066

Dong, S., Chen, X., Gu, L., Zhou, X., Wang, H., Liu, Z., et al. (2011). Tin/vn composites with core/shell structure for supercapacitors. Mater. Res. Bull. 46, 835-839. doi: 10.1016/j.materresbull.2011.02.028

Dong, S., Chen, X., Zhang, X., and Cui, G. (2013). Nanostructured transition metal nitrides for energy storage and fuel cells. Coord. Chem. Rev. 257, 1946-1956. doi: 10.1016/j.ccr.2012.12.012

Dutta, S., Indra, A., Feng, Y., Han, H., and Song, T. (2019). Promoting electrocatalytic overall water splitting with nanohybrid of transition metal nitride-oxynitride. Appl. Catal. B 241, 521-527. doi: 10.1016/j.apcatb.2018.09.061

El Himri, A., El Himri, M., Pérez-Coll, D., and Núñez, P. (2015). Co-precipitate precursor-based synthesis of new interstitial niobium molybdenum nitrides. Res. Chem. Intermed. 41, 6397-6407. doi: 10.1007/s11164-014-1749-8

Eustache, E., Frappier, R., Porto, R. L., Bouhtiyya, S., Pierson, J.-F., and Brousse, T. (2013). Asymmetric electrochemical capacitor microdevice designed with vanadium nitride and nickel oxide thin film electrodes. Electrochem. Commun. 28, 104-106. doi: 10.1016/j.elecom.2012.12.015

Gandi, A. N., Alshareef, H. N., and Schwingenschlögl, U. (2016). Thermoelectric performance of the mxenes $\mathrm{M}_{2} \mathrm{Co}_{2}(\mathrm{~m}=\mathrm{ti}$, zr, or hf). Chem. Mater. 28, 1647-1652. doi: 10.1021/acs.chemmater.5b04257

Gao, X., Zhou, D., Chen, Y., Wu, W., Su, D., Li, B., et al. (2019). Strong charge polarization effect enabled by surface oxidized titanium nitride for lithiumsulfur batteries. Commun. Chem. 2, 1-10. doi: 10.1038/s42004-019-0166-8

Gao, Z., Wu, Z., Zhao, S., Zhang, T., and Wang, Q. (2019). Enhanced capacitive property of hfn film electrode by plasma etching for supercapacitors. Mater. Lett. 235, 148-152. doi: 10.1016/j.matlet.2018.10.032

Ghidiu, M., Lukatskaya, M. R., Zhao, M.-Q., Gogotsi, Y., and Barsoum, M. W. (2014). Conductive two-dimensional titanium carbide 'clay'with high volumetric capacitance. Nature 516:78. doi: 10.1038/nature13970

Ghimbeu, C. M., Raymundo-Piñero, E., Fioux, P., Béguin, F., and Vix-Guterl, C. (2011). Vanadium nitride/carbon nanotube nanocomposites as electrodes for supercapacitors. J. Mater. Chem. 21, 13268-13275. doi: 10.1039/c1jm11014d

Giordano, C., and Antonietti, M. (2011). Synthesis of crystalline metal nitride and metal carbide nanostructures by sol-gel chemistry. Nano Today 6, 366-380. doi: 10.1016/j.nantod.2011.06.002

Glushenkov, A. M., Hulicova-Jurcakova, D., Llewellyn, D., Lu, G. Q., and Chen, Y. (2010). Structure and capacitive properties of porous nanocrystalline vn prepared by temperature-programmed ammonia reduction of $\mathrm{V}_{2} \mathrm{O}_{5}$. Chem. Mater. 22, 914-921. doi: 10.1021/cm901729x

Guan, C., Xia, X., Meng, N., Zeng, Z., Cao, X., Soci, C., et al. (2012). Hollow coreshell nanostructure supercapacitor electrodes: gap matters. Energy Environ. Sci. 5, 9085-9090. doi: 10.1039/c2ee22815g

Guo, Z., Liu, J., Jia, Y., Chen, X., Meng, F., Li, M., et al. (2008). Template synthesis, organic gas-sensing and optical properties of hollow and porous $\mathrm{In}_{2} \mathrm{O}_{3}$ nanospheres. Nanotechnology 19:345704. doi: 10.1088/0957-4484/19/34/345704

Hadjipanayis, G., Wang, Y., Singleton, E., and Yelon, W. (1992). Rare-earth nitrides and carbides: a new class of permanent magnet materials. J. Mater. Eng. Perform. 1, 193-203. doi: 10.1007/BF02648617

Hadjipanayis, G. C. (1999). Nanophase hard magnets. J. Magn. Magn. Mater. 200, 373-391. doi: 10.1016/S0304-8853(99)00430-8

He, C.-L., Zhang, J.-L., Xie, L.-P., Ma, G.-F., Du, Z.-F., Wang, J.M., et al. (2019). Microstructure, mechanical and corrosion properties of tin/ni nanomultilayered films. Rare Met. 38, 979-988. doi: 10.1007/s12598-018-1154-3

He, T., Zhang, W., Manasa, P., and Ran, F. (2020). Quantum dots of molybdenum nitride embedded in continuously distributed polyaniline as novel electrode material for supercapacitor. J. Alloys Compd. 812:152138. doi: 10.1016/j.jallcom.2019.152138

He, Z., Xiao, B., Liu, F., Wu, H., Yang, Y., Xiao, S., et al. (2015). Single-junction polymer solar cells with high efficiency and photovoltage. Nat. Photonics 9:174. doi: 10.1038/nphoton.2015.6

Higgins, D. C., Choi, J.-Y., Wu, J., Lopez, A., and Chen, Z. (2012). Titanium nitride-carbon nanotube core-shell composites as effective electrocatalyst supports for low temperature fuel cells. J. Mater. Chem. 22, 3727-3732. doi: $10.1039 / \mathrm{c} 2 \mathrm{jm} 15014 \mathrm{j}$

Hu, Y., Yang, H., Chen, J., Xiong, T., Balogun, M.-S. J. T., and Tong, Y. (2019). Efficient hydrogen evolution activity and overall water splitting of metallic $\mathrm{Co}_{4} \mathrm{~N}$ nanowires through tunable d-orbitals with ultrafast incorporation of feooh. ACS Appl. Mater. Interfaces 11, 5152-5158. doi: 10.1021/acsami. $8 \mathrm{~b} 20717$

Huang, H., Gao, S., Wu, A.-M., Cheng, K., Li, X.-N., Gao, X.-X., et al. (2017). $\mathrm{Fe}_{3} \mathrm{~N}$ constrained inside $\mathrm{c}$ nanocages as an anode for li-ion batteries through post-synthesis nitridation. Nano Energy 31, 74-83. doi: 10.1016/j.nanoen.2016.10.059

Hugosson, H. W., Eriksson, O., Jansson, U., Ruban, A. V., Souvatzis, P., and Abrikosov, I. (2004). Surface energies and work functions of the transition metal carbides. Surf. Sci. 557, 243-254. doi: 10.1016/j.susc. 2004 . 03.050

Jansen, S. A., and Hoffmann, R. (1988). Surface chemistry of transition metal carbides: a theoretical analysis. Surf. Sci. 197, 474-508. doi: 10.1016/0039-6028(88)90641-3 
Jia, H., Cai, Y., Li, S., Zheng, X., Miao, L., Wang, Z., et al. (2020). In situ synthesis of core-shell vanadium nitride@ n-doped carbon microsheet sponges as highperformance anode materials for solid-state supercapacitors. J. Colloid Interface Sci. 560, 122-129. doi: 10.1016/j.jcis.2019.10.061

Jiang, G., Han, H., Zhuang, W., Xu, X., Kaskel, S., Xu, F., et al. (2019). Three-dimensional ordered mesoporous cobalt nitride for fast-kinetics and stable-cycling lithium storage. J. Mater. Chem. A 7, 17561-17569. doi: 10.1039/C9TA03391B

Jiang, Q., Kurra, N., Alhabeb, M., Gogotsi, Y., and Alshareef, H. N. (2018). All pseudocapacitive mxene-ruo2 asymmetric supercapacitors. Adv. Energy Mater. 8:1703043. doi: 10.1002/aenm.201703043

Jin, H., Liu, X., Vasileff, A., Jiao, Y., Zhao, Y., Zheng, Y., et al. (2018). Single-crystal nitrogen-rich two-dimensional $\mathrm{Mo}_{5} \mathrm{~N}_{6}$ nanosheets for efficient and stable seawater splitting. ACS Nano 12, 12761-12769. doi: 10.1021/acsnano.8b07841

Jin, T., Sang, X., Unocic, R. R., Kinch, R. T., Liu, X., Hu, J., et al. (2018). Mechanochemical-assisted synthesis of high-entropy metal nitride via a soft urea strategy. Adv. Mater. 30:1707512. doi: 10.1002/adma.201707512

Kan, X., Ding, J., Zhu, H., Deng, C., and Yu, C. (2017). Low temperature synthesis of nanoscale titanium nitride via molten-salt-mediated magnesiothermic reduction. Powder Technol. 315, 81-86. doi: 10.1016/j.powtec.2017.03.042

Kang, J. S., Park, M.-A., Kim, J.-Y., Park, S. H., Chung, D. Y., Yu, S.-H., et al. (2015). Reactively sputtered nickel nitride as electrocatalytic counter electrode for dye-and quantum dot-sensitized solar cells. Sci. Rep. 5:10450. doi: 10.1038/srep10450

Kang, K., Meng, Y. S., Bréger, J., Grey, C. P., and Ceder, G. (2006). Electrodes with high power and high capacity for rechargeable lithium batteries. Science 311, 977-980. doi: 10.1126/science.1122152

Kao, E., Yang, C., Warren, R., Kozinda, A., and Lin, L. (2016). Ald titanium nitride on vertically aligned carbon nanotube forests for electrochemical supercapacitors. Sensor Actuat. A Phys. 240, 160-166. doi: 10.1016/j.sna.2016.01.044

Karan, N., Agrawal, A., Pandey, P., Smitha, P., Sharma, S., Mishra, D., et al. (2009). Diffusion flame synthesis of hollow, anatase $\mathrm{TiO}_{2}$ nanoparticles. Mat. Sci. Eng. B 163, 128-133. doi: 10.1016/j.mseb.2009.05.005

Khazaei, M., Ranjbar, A., Arai, M., and Yunoki, S. (2016). Topological insulators in the ordered double transition metals $\mathrm{m} 2^{\prime} \mathrm{m}{ }^{\prime \prime} \mathrm{c} 2$ mxenes $\left(\mathrm{m}^{\prime}=\mathrm{mo}, \mathrm{w} ; \mathrm{m}\right.$ " = ti, zr, hf). Phys. Rev. B 94:125152. doi: 10.1103/PhysRevB.94.125152

Kibria, M. G., Nguyen, H. P., Cui, K., Zhao, S., Liu, D., Guo, H., et al. (2013). One-step overall water splitting under visible light using multiband ingan/GaN nanowire heterostructures. ACS Nano 7, 7886-7893. doi: 10.1021/nn4028823

Kim, B. H., Onses, M. S., Lim, J. B., Nam, S., Oh, N., Kim, H., et al. (2015). High-resolution patterns of quantum dots formed by electrohydrodynamic jet printing for light-emitting diodes. Nano Lett. 15, 969-973. doi: $10.1021 / \mathrm{nl} 503779 \mathrm{e}$

Kundu, D., Krumeich, F., Fotedar, R., and Nesper, R. (2015). A nanocrystalline nitride as an insertion anode for li-ion batteries. J. Power Sources 278, 608-613. doi: 10.1016/j.jpowsour.2014.12.087

Lai, L., Zhu, J., Li, B., Zhen, Y., Shen, Z., Yan, Q., et al. (2014). One novel and universal method to prepare transition metal nitrides doped graphene anodes for li-ion battery. Electrochim. Act 134, 28-34. doi: 10.1016/j.electacta.2014.04.073

Li, C.-T., Li, S.-R., Chang, L.-Y., Lee, C.-P., Chen, P.-Y., Sun, S.-S., et al. (2015). Efficient titanium nitride/titanium oxide composite photoanodes for dyesensitized solar cells and water splitting. J. Mater. Chem. A 3, 4695-4705. doi: 10.1039/C4TA05606J

Li, L., Zhang, M., Zhang, X., and Zhang, Z. (2017). New $\mathrm{Ti}_{3} \mathrm{C}_{2}$ aerogel as promising negative electrode materials for asymmetric supercapacitors. J. Power Sources 364, 234-241. doi: 10.1016/j.jpowsour.2017.08.029

Liu, G., Pan, Z., Zhang, B., Xiao, J., Xia, G., Zhao, Q., et al. (2017). A novel tin coated cnts nanocomposite cnts@ tin supported pt electrocatalyst with enhanced catalytic activity and durability for methanol oxidation reaction. Int. J. Hydrog. Energy 42, 12467-12476. doi: 10.1016/j.ijhydene.2017.03.181

Liu, J., Zhang, H. B., Sun, R., Liu, Y., Liu, Z., Zhou, A., et al. (2017). Hydrophobic, flexible, and lightweight mxene foams for high-performance electromagneticinterference shielding. Adv. Mater. 29:1702367. doi: 10.1002/adma.201702367

Liu, S.-L., Huang, J., Liu, J., Lei, M., Min, J., Li, S., et al. (2016). Porous $\mathrm{Mo}_{2} \mathrm{~N}$ nanobelts as a new anode material for sodium-ion batteries. Mater. Lett. 172, 56-59. doi: 10.1016/j.matlet.2016.02.121
Liu, Y., Liu, L., Kong, L., Kang, L., and Ran, F. (2016). Supercapacitor electrode based on nano-vanadium nitride incorporated on porous carbon nanospheres derived from ionic amphiphilic block copolymers \& vanadium-contained ion assembly systems. Electrochim. Act 211, 469-477. doi: 10.1016/j.electacta.2016.06.058

Lu, X., Wang, G., Zhai, T., Yu, M., Xie, S., Ling, Y., et al. (2012). Stabilized tin nanowire arrays for high-performance and flexible supercapacitors. Nano Lett.12, 5376-5381. doi: 10.1021/nl302761z

Lu, X., Yu, M., Zhai, T., Wang, G., Xie, S., Liu, T., et al. (2013). High energy density asymmetric quasi-solid-state supercapacitor based on porous vanadium nitride nanowire anode. Nano Lett. 13, 2628-2633. doi: 10.1021/nl400760a

Lucio-Porto, R., Bouhtiyya, S., Pierson, J.-F., Morel, A., Capon, F., Boulet, P., et al. (2014). Vn thin films as electrode materials for electrochemical capacitors. Electrochim. Act 141, 203-211. doi: 10.1016/j.electacta.2014.07.056

Lukatskaya, M. R., Mashtalir, O., Ren, C. E., Dall'Agnese, Y., Rozier, P., Taberna, P. L., et al. (2013). Cation intercalation and high volumetric capacitance of two-dimensional titanium carbide. Science 341, 1502-1505. doi: $10.1126 /$ science. 1241488

Luo, K., Liu, Y., Wang, F., Gao, M., and Pan, H. (2009). Hydrogen storage in a li-al-n ternary system. Int. J. Hydrog. Energy 34, 8101-8107. doi: 10.1016/j.ijhydene.2009.07.078

Mohamed, S., Zhao, H., Romanus, H., El-Hossary, F. M., Abo EL-Kassem, M., Awad, M., et al. (2020). Optical, water splitting and wettability of titanium nitride/titanium oxynitride bilayer films for hydrogen generation and solar cells applications. Mater. Sci. Semicond. Process. 105:104704. doi: 10.1016/j.mssp.2019.104704

Morel, A., Borjon-Piron, Y., Porto, R. L., Brousse, T., and Bélanger, D. (2016). Suitable conditions for the use of vanadium nitride as an electrode for electrochemical capacitor. J. Electrochem. Soc. 163, A1077-A1082. doi: $10.1149 / 2.1221606$ jes

Naguib, M., Halim, J., Lu, J., Cook, K. M., Hultman, L., Gogotsi, Y., et al. (2013). New two-dimensional niobium and vanadium carbides as promising materials for li-ion batteries. J. Am. Chem. Soc. 135, 15966-15969. doi: 10.1021/ja405735d

Naik, G. V., Schroeder, J. L., Ni, X., Kildishev, A. V., Sands, T. D., and Boltasseva, A. (2012). Titanium nitride as a plasmonic material for visible and near-infrared wavelengths. Opt. Mater. Express. 2, 478-489. doi: 10.1364/OME.2.000478

Nakamura, S. (2015). Nobel lecture: background story of the invention of efficient blue ingan light emitting diodes. Rev. Mod. Phys. 87:1139-1151. doi: 10.1002/andp.201500801

Nandi, D. K., Sen, U. K., Choudhury, D., Mitra, S., and Sarkar, S. K. (2014) Atomic layer deposited molybdenum nitride thin film: a promising anode material for li ion batteries. ACS Appl. Mater. Interfaces 6, 6606-6615. doi: $10.1021 / \mathrm{am} 500285 \mathrm{~d}$

Nelson, J. A., and Wagner, M. J. (2002). High surface area $\mathrm{Mo}_{2} \mathrm{C}$ and wc prepared by alkalide reduction. Chem. Mater. 14, 1639-1642. doi: 10.1021/cm0107833

Odahara, J., Sun, W., Miura, A., Rosero-Navarro, N. C., Nagao, M., Tanaka, I., et al. (2019). Self-combustion synthesis of novel metastable ternary molybdenum nitrides. ACS Mater. Lett. 1, 64-70. doi: 10.1021/acsmaterialslett.9b00057

Oyama, S. (1992). Preparation and catalytic properties of transition metal carbides and nitrides. Catal. Today 15, 179-200. doi: 10.1016/0920-5861(92)80175-M

Oyama, S. T. (1996). "Introduction to the chemistry of transition metal carbides and nitrides," in The Chemistry of Transition Metal Carbides and Nitrides (Blacksburg, VA, Department of Chemical Engineering, Virginia Polytechnic Institute and State University), 1-27.

Pan, Z., Cao, F., Hu, X., and Ji, X. (2019). A facile method for synthesizing cus decorated $\mathrm{Ti}_{3} \mathrm{C}_{2}$ mxene with enhanced performance for asymmetric supercapacitors. J. Mater. Chem. A 7, 8984-8992. doi: 10.1039/C9TA0 0085B

Panda, R., and Gajbhiye, N. (1997). Magnetic properties of single domain $\varepsilon$ $\mathrm{Fe}_{3} \mathrm{~N}$ synthesized by borohydride reduction route. J. Appl. Phys. 81, 335-339. doi: $10.1063 / 1.364115$

Rakhi, R. B., Chen, W., Cha, D., and Alshareef, H. N. (2012). Nanostructured ternary electrodes for energy-storage applications. Adv. Energy Mater. 2, 381-389. doi: 10.1002/aenm.201100609

Ran, J., Gao, G., Li, F.-T., Ma, T.-Y., Du, A., and Qiao, S.-Z. (2017). $\mathrm{Ti}_{3} \mathrm{C}_{2}$ mxene co-catalyst on metal sulfide photo-absorbers for enhanced visible-light photocatalytic hydrogen production. Nat. Commun 8:13907. doi: $10.1038 /$ ncomms 13907 
Rohmer, M.-M., Bénard, M., and Poblet, J.-M. (2000). Structure, reactivity, and growth pathways of metallocarbohedrenes $\mathrm{M}_{8} \mathrm{Cl}_{2}$ and transition metal/carbon clusters and nanocrystals: a challenge to computational chemistry. Chem. Rev. 100, 495-542. doi: 10.1021/cr9803885

Roy, T., Tosun, M., Cao, X., Fang, H., Lien, D.-H., Zhao, P., et al. (2015). Dualgated $\mathrm{MoS}_{2} / \mathrm{WSe}_{2}$ van der waals tunnel diodes and transistors. ACS Nano 9, 2071-2079. doi: 10.1021/nn507278b

Schaaf, P., Kahle, M., and Carpene, E. (2005). Reactive laser synthesis of carbides and nitrides. Appl. Surf. Sci. 247, 607-615. doi: 10.1016/j.apsusc.2005.01.128

Schnepp, Z., Thomas, M., Glatzel, S., Schlichte, K., Palkovits, R., and Giordano, C. (2011). One pot route to sponge-like $\mathrm{Fe}_{3} \mathrm{~N}$ nanostructures. J. Mater. Chem. 21, 17760-17764. doi: $10.1039 / \mathrm{cljm} 12842 \mathrm{f}$

Seifitokaldani, A., and Savadogo, O. (2015). Electrochemically stable titanium oxynitride support for platinum electro-catalyst for pem fuel cell applications. Electrochim. Acta 167, 237-245. doi: 10.1016/j.electacta.2015.03.189

Shah, S. I. U., Hector, A. L., and Owen, J. R. (2014). Redox supercapacitor performance of nanocrystalline molybdenum nitrides obtained by ammonolysis of chloride-and amide-derived precursors. J. Power Sources 266, 456-463. doi: 10.1016/j.jpowsour.2014.05.045

Shahzad, F., Alhabeb, M., Hatter, C. B., Anasori, B., Hong, S. M., Koo, C. M., et al. (2016). Electromagnetic interference shielding with $2 \mathrm{~d}$ transition metal carbides (mxenes). Science 353, 1137-1140. doi: 10.1126/science.aag2421

Shalom, M., Ressnig, D., Yang, X., Clavel, G., Fellinger, T. P., and Antonietti, M. (2015). Nickel nitride as an efficient electrocatalyst for water splitting. J. Mater. Chem. A 3, 8171-8177. doi: 10.1039/C5TA00078E

Shen, H., Wei, B., Zhang, D., Qi, Z., and Wang, Z. (2018). Magnetron sputtered nbn thin film electrodes for supercapacitors. Mater. Lett. 229, 17-20. doi: 10.1016/j.matlet.2018.06.052

Sheng, W.-J., Yang, X., Zhu, J., Wang, C., and Zhang, Y. (2018). Amorphous phase stability of nbtialsin x high-entropy films. Rare Met. 37, 682-689. doi: 10.1007/s12598-016-0840-2

Shi, H., Sun, Z., Lv, W., Xiao, S., Yang, H., Shi, Y., et al. (2020). Efficient polysulfide blocker from conductive niobium nitride@ graphene for li-s batteries. J. Energy Chem. 45, 135-141. doi: 10.1016/j.jechem.201 9.10 .018

Shi, Y., Wan, Y., Zhang, R., and Zhao, D. (2008). Synthesis of self-supported ordered mesoporous cobalt and chromium nitrides. Adv. Funct. Mater. 18, 2436-2443. doi: 10.1002/adfm.200800488

Siegel, E. (1979). D-bandwidth contraction upon metalloid formation-resolution of the bonding controversy in transition-metal carbides, nitrides and borides. Semiconduc. Insul. 5, 47-60.

Sinev, I., Komissarenko, F., Mukhin, I., Petrov, M., Iorsh, I., Belov, P., et al. (2018). Near-field optical microscopy of surface plasmon polaritons excited by silicon nanoantenna. Nanosyst. Phys. Chem. Math. 9, 609-613. doi: 10.17586/2220-8054-2018-9-5-609-613

Song, G.-T., Wang, Y., Qi, Y., Li, W.-M., and Zhang, L.-X. (2019). Fabrication of titanium nitride nanoparticles onto carbon nanotubes by atomic layer deposition for utilization as pt electrocatalyst supports. Rare Metals 39, 1-8. doi: 10.1007/s12598-019-01284-5

Soundiraraju, B., and George, B. K. (2017). Two-dimensional titanium nitride $\left(\mathrm{Ti}_{2} \mathrm{~N}\right)$ mxene: synthesis, characterization, and potential application as surface-enhanced raman scattering substrate. ACS Nano 11, 8892-8900. doi: 10.1021/acsnano.7b03129

$\mathrm{Su}$, Y., and Zhitomirsky, I. (2014). Hybrid $\mathrm{MnO}_{2} /$ carbon nanotubevn/carbon nanotube supercapacitors. J. Power Sources 267, 235-242. doi: 10.1016/j.jpowsour.2014.05.091

Sun, C., Tang, X., Yin, Z., Liu, D., Wang, Y.-J., Yang, G., et al. (2020). Self-supported $\mathrm{GaN}$ nanowires with cation-defects, lattice distortion, and abundant active sites for high-rate lithium-ion storage. Nano Energy 68:104376. doi: 10.1016/j.nanoen.2019.104376

Sun, C., Yang, M., Wang, T., Shao, Y., Wu, Y., and Hao, X. (2017). Graphene-oxide-assisted synthesis of $\mathrm{GaN}$ nanosheets as a new anode material for lithium-ion battery. ACS Appl. Mater. Interfaces 9, 26631-26636. doi: 10.1021/acsami.7b07277

Tian, X. L., Wang, L., Chi, B., Xu, Y., Zaman, S., Qi, K., et al. (2018). Formation of a tubular assembly by ultrathin $\mathrm{Ti}_{0.8} \mathrm{Co}_{0.2} \mathrm{~N}$ nanosheets as efficient oxygen reduction electrocatalysts for hydrogen-/metal-air fuel cells. ACS Catal. 8, 8970-8975. doi: 10.1021/acscatal.8b02710
Venkateshalu, S., and Grace, A. N. (2020). $\mathrm{Ti}_{3} \mathrm{C}_{2} \mathrm{~T}_{\mathrm{x}}$ mxene and vanadium nitride/porous carbon as electrodes for asymmetric supercapacitors. Electrochim. Acta 341:136035. doi: 10.1016/j.electacta.2020.136035

Vissokov, G., Grancharov, I., and Tsvetanov, T. (2003). On the plasmachemical synthesis of nanopowders. Plasma Sci. Technol. 5:2039-2050. doi: 10.1088/1009-0630/5/6/005

Volpe, L., and Boudart, M. (1985). Compounds of molybdenum and tungsten with high specific surface area: I. Nitrides. J. Solid State Chem. 59, 332-347. doi: 10.1016/0022-4596(85)90301-9

Wang, D., Pierre, A., Kibria, M. G., Cui, K., Han, X., Bevan, K. H., et al. (2011). Wafer-level photocatalytic water splitting on $\mathrm{GaN}$ nanowire arrays grown by molecular beam epitaxy. Nano Lett. 11, 2353-2357. doi: 10.1021/nl2006802

Wang, F., Xiao, S., Hou, Y., Hu, C., Liu, L., and Wu, Y. (2013). Electrode materials for aqueous asymmetric supercapacitors. RSC Adv. 3, 13059-13084. doi: 10.1039/c3ra23466e

Wang, G., Hou, S., Yan, C., Lin, Y., and Liu, S. (2017). Three-dimensional porous vanadium nitride nanoribbon aerogels as pt-free counter electrode for high-performance dye-sensitized solar cells. Chem. Eng. J 322, 611-617. doi: $10.1016 /$ j.cej.2017.04.066

Wang, G., Lu, X., Ling, Y., Zhai, T., Wang, H., Tong, Y., et al. (2012). Licl/pva gel electrolyte stabilizes vanadium oxide nanowire electrodes for pseudocapacitors. ACS Nano 6, 10296-10302. doi: 10.1021/nn304178b

Wang, J., Yang, C., Wang, J., Han, L., and Wei, M. (2019). Two-dimensional mon@n-doped carbon hollow spheres as an anode material for high performance lithium-ion battery. Electrochim. Acta 295, 246-252. doi: 10.1016/j.electacta.2018.10.159

Wang, L., Fan, G., Xu, X., Chen, D., Wang, L., Shi, W., et al. (2017). Detection of polychlorinated benzenes (persistent organic pollutants) by a luminescent sensor based on a lanthanide metal-organic framework. J. Mater. Chem. A 5, 5541-5549. doi: 10.1039/C7TA00256D

Wang, P., Tang, S., Huang, P., and Lei, A. (2017). Electrocatalytic oxidantfree dehydrogenative $\mathrm{c}-\mathrm{h} / \mathrm{s}-\mathrm{h}$ cross-coupling. Angew. Chem. Int. Ed. 56, 3009-3013. doi: 10.1002/anie.201700012

Wang, R., Lang, J., Zhang, P., Lin, Z., and Yan, X. (2015). Fast and large lithium storage in $3 \mathrm{~d}$ porous vn nanowires-graphene composite as a superior anode toward high-performance hybrid supercapacitors. Adv. Funct. Mater. 25, 2270-2278. doi: 10.1002/adfm.201404472

Wang, S., Ge, H., Han, W., Li, Y., Zhang, J., Yu, X., et al. (2017). Synthesis of onion-like $\delta$-mon catalyst for selective hydrogenation. J. Phys. Chem. C. 121, 19451-19460. doi: 10.1021/acs.jpcc.7b05460

Wang, Y., Xie, C., Liu, D., Huang, X., Huo, J., and Wang, S. (2016). Nanoparticlestacked porous nickel-iron nitride nanosheet: a highly efficient bifunctional electrocatalyst for overall water splitting. ACS Appl. Mater. Interfaces 8, 18652-18657. doi: 10.1021/acsami.6b05811

Wei, B., Mei, G., Liang, H., Qi, Z., Zhang, D., Shen, H., et al. (2018). Porous crn thin films by selectively etching crcun for symmetric supercapacitors. J. Power Sources 385, 39-44. doi: 10.1016/j.jpowsour.2018.03.023

Wild, S., Grieveson, P., Jack, K., and Latimer, M. (1972). "The role of magnesia in hot-pressed silicon nitride," in Special Ceramics, 5th Edn. ed P. Popper (Stoke-on-Trent: British Ceramic Research Association), 271-281.

Wu, H., and Chen, W. (2011). Copper nitride nanocubes: size-controlled synthesis and application as cathode catalyst in alkaline fuel cells. J. Am. Chem. Soc.133, 15236-15239. doi: 10.1021/ja204748u

Wu, H., Qin, M., Cao, Z., Li, X., Jia, B., and Qu, X. (2019). Highly efficient synthesis of $2 \mathrm{~d}$ vn nanoparticles/carbon sheet nanocomposites and their application as supercapacitor electrodes. Appl. Surf. Sci. 466, 982-988. doi: 10.1016/j.apsusc.2018.10.102

$\mathrm{Wu}, \mathrm{M}$. X., and Yang, Y. W. (2017). Metal-organic framework (mof)based drug/cargo delivery and cancer therapy. Adv. Mater. 29:1606134 doi: 10.1002/adma.201606134

Xi, S., Lin, G., Jin, L., Li, H., and Xie, K. (2019). Metallic porous nitride single crystals at two-centimeter scale delivering enhanced pseudocapacitance. Nat. Commun. 10, 1-9. doi: 10.1038/s41467-019-12818-x

Xiao, X., Yu, H., Jin, H., Wu, M., Fang, Y., Sun, J., et al. (2017). Salt-templated synthesis of $2 \mathrm{~d}$ metallic mon and other nitrides. ACS Nano 11, 2180-2186. doi: 10.1021/acsnano.6b08534

Xie, J., Li, S., Zhang, X., Zhang, J., Wang, R., Zhang, H., et al. (2014). Atomically-thin molybdenum nitride nanosheets with exposed active 
surface sites for efficient hydrogen evolution. Chem. Sci. 5, 4615-4620. doi: 10.1039/C4SC02019G

Xu, K., Shen, Y., Zhang, K., Yang, F., Li, S., and Hu, J. (2019). Hierarchical assembly of manganese dioxide nanosheets on one-dimensional titanium nitride nanofibers for high-performance supercapacitors. J. Colloid Interface Sci. 552, 712-718. doi: 10.1016/j.jcis.2019.05.093

Yang, Y., Shen, K., Liu, Y., Tan, Y., Zhao, X., Wu, J., et al. (2017). Novel hybrid nanoparticles of vanadium nitride/porous carbon as an anode material for symmetrical supercapacitor. Nano Micro Lett. 9:6. doi: 10.1007/s40820-016-0105-5

Yang, Z., Qiao, S., Sun, S., and Hou, Y. (2017). "Overview of magnetic nanomaterials," in Magnetic Nanomaterials: Fundamentals, Synthesis and Applications, eds Y. Hou and D. J. Sellmyer (John Wiley \& Sons). doi: 10.1002/9783527803255.ch1

Yao, W., Makowski, P., Giordano, C., and Goettmann, F. (2009). Synthesis of early-transition-metal carbide and nitride nanoparticles through the urea route and their use as alkylation catalysts. Chem. Eur. J. 15, 11999-12004. doi: 10.1002/chem.200901496

Yazdan, A., Wang, J.-Z., Hu, B.-K., Xie, W.-S., Zhao, L.-Y., Nan, C.-W., et al. (2019). Boron nitride/agarose hydrogel composites with high thermal conductivities. Rare Metals 39, 1-8. doi: 10.1007/s12598-019-01322-2

Yin, Z., Sun, Y., Jiang, Y., Yan, F., Zhu, C., and Chen, Y. (2019). Hierarchical cobalt-doped molybdenum-nickel nitride nanowires as multifunctional electrocatalysts. ACS Appl. Mater. Interfaces 11, 27751-27759. doi: 10.1021/acsami.9b06543

Yu, H., Yang, X., Xiao, X., Chen, M., Zhang, Q., Huang, L., et al. (2018). Atmospheric-pressure synthesis of $2 \mathrm{~d}$ nitrogen-rich tungsten nitride. $A d v$. Mater. 30:1805655. doi: 10.1002/adma.201805655

Yu, L.-Y., Xu, Z.-L., Shen, H.-M., and Yang, H. (2009). Preparation and characterization of pvdf-SiO ${ }_{2}$ composite hollow fiber uf membrane by sol-gel method. J. Membr. Sci. 337, 257-265. doi: 10.1016/j.memsci.2009.03.054

Yuan, J., Hu, X., Chen, J., Liu, Y., Huang, T., and Wen, Z. (2019a). In-situ formation of vanadium nitride quantum dots on n-doped carbon hollow spheres for superior lithium and sodium storage. J. Mater. Chem. A. 7:9289-9296.

Yuan, J., Hu, X., Chen, J., Liu, Y., Huang, T., and Wen, Z. (2019b). In situ formation of vanadium nitride quantum dots on $\mathrm{n}$-doped carbon hollow spheres for superior lithium and sodium storage. J. Mater. Chem. A 7, 9289-9296. doi: 10.1039/C8TA12512K

Zhang, B., Cui, G., Zhang, K., Zhang, L., Han, P., and Dong, S. (2014). Molybdenum nitride/nitrogen-doped graphene hybrid material for lithium storage in lithium ion batteries. Electrochim. Acta 150, 15-22. doi: 10.1016/j.electacta.2014.10.113

Zhang, B., Xiao, C., Xie, S., Liang, J., Chen, X., and Tang, Y. (2016). Iron-nickel nitride nanostructures in situ grown on surface-redox-etching nickel foam: efficient and ultrasustainable electrocatalysts for overall water splitting. Chem. Mater. 28, 6934-6941. doi: 10.1021/acs.chemmater.6b02610

Zhang, J., Zhang, J., Peng, Z., Cai, W., Yu, L., Wu, Z., et al. (2014). Outstanding rate capability and long cycle stability induced by homogeneous distribution of nitrogen doped carbon and titanium nitride on the surface and in the bulk of spinel lithium titanate. Electrochim. Acta 132, 230-238. doi: 10.1016/j.electacta.2014.03.007

Zhang, L., Holt, C. M., Luber, E. J., Olsen, B. C., Wang, H., Danaie, M., et al. (2011). High rate electrochemical capacitors from three-dimensional arrays of vanadium nitride functionalized carbon nanotubes. J. Phys. Chem. C 115, 24381-24393. doi: 10.1021/jp205052f

Zhang, P., Wang, X., Wang, W., Lei, X., and Yang, H. (2015). Magnetic and hydrazine-decomposition catalytic properties of $\varepsilon-\mathrm{Fe}_{3} \mathrm{~N}$ synthesized from a novel precursor. J. Mater. Chem. A 3, 6464-6469. doi: 10.1039/C4TA0 6810F

Zhang, Q., Wang, X., Pan, Z., Sun, J., Zhao, J., Zhang, J., et al. (2017). Wrapping aligned carbon nanotube composite sheets around vanadium nitride nanowire arrays for asymmetric coaxial fiber-shaped supercapacitors with ultrahigh energy density. Nano Lett. 17, 2719-2726. doi: 10.1021/acs.nanolett.7b00854

Zhang, S., Wen, Y., and Zhang, H. (2014). Low temperature preparation of tungsten nanoparticles from molten salt. Powder Technol. 253, 464-466. doi: 10.1016/j.powtec.2013.11.052

Zhang, Y., Ouyang, B., Xu, J., Jia, G., Chen, S., Rawat, R. S., et al. (2016). Rapid synthesis of cobalt nitride nanowires: highly efficient and low-cost catalysts for oxygen evolution. Angew. Chem. Int. Ed. 55, 8670-8674. doi: 10.1002/anie.201604372

Zhao, G., Cheng, Y., Sun, P., Ma, W., Hao, S., Wang, X., et al. (2020). Biocarbon based template synthesis of uniform lamellar $\mathrm{MoS}_{2}$ nanoflowers with excellent energy storage performance in lithium-ion battery and supercapacitors. Electrochim. Acta 331:135262. doi: 10.1016/j.electacta.2019.135262

Zhao, G., Cheng, Y., Wu, Y., Xu, X., and Hao, X. (2018a). New 2d carbon nitride organic materials synthesis with huge-application prospects in $\mathrm{cn}$ photocatalyst. Small 14, 1704138. doi: 10.1002/smll.201704138

Zhao, G., Wang, A., He, W., Xing, Y., and Xu, X. (2019). 2d new nonmetal photocatalyst of sulfur-doped h-bn nanosheeets with high photocatalytic activity. Adv. Mater. Interfaces 6:1900062. doi: 10.1002/admi.201900062

Zhao, G., Yang, H., Liu, M., and Xu, X. (2018b). Metal-free graphitic carbon nitride photocatalyst goes into two-dimensional time. Front. Chem. 6:551. doi: 10.3389/fchem.2018.00551

Zhao, H., Li, Y., Liu, R., Zhao, F., and Hu, Y. (2008). Synthesis method for silica needle-shaped nano-hollow structure. Mater. Lett. 62, 3401-3403. doi: 10.1016/j.matlet.2008.03.020

Zhao, M. Q., Ren, C. E., Ling, Z., Lukatskaya, M. R., Zhang, C., Van Aken, K. L., et al. (2015). Flexible mxene/carbon nanotube composite paper with high volumetric capacitance. Adv. Mater. 27, 339-345. doi: 10.1002/adma.201404140

Zhou, Z., Li, Q., Yuan, L., Tang, L., Wang, X., He, B., et al. (2020). Achieving ultrahigh-energy-density in flexible and lightweight all-solid-state internal asymmetric tandem $6.6 \mathrm{v}$ all-in-one supercapacitors. Energy Storage Mater. 25, 893-902. doi: 10.1016/j.ensm.2019.09.002

Zhu, C., Yang, P., Chao, D., Wang, X., Zhang, X., Chen, S., et al. (2015). All metal nitrides solid-state asymmetric supercapacitors. Adv. Mater. 27, 4566-4571. doi: 10.1002/adma.201501838

Zhu, C., Yin, Z., Lai, W., Sun, Y., Liu, L., Zhang, X., et al. (2018). Fe-ni-mo nitride porous nanotubes for full water splitting and $\mathrm{Zn}$-air batteries. Adv. Energy Mater. 8:1802327. doi: 10.1002/aenm.201802327

Zou, R., Xu, M., He, S.-A., Han, X., Lin, R., Cui, Z., et al. (2018). Cobalt nickel nitride coated by a thin carbon layer anchoring on nitrogen-doped carbon nanotube anodes for high-performance lithium-ion batteries. J. Mater. Chem. A 6, 19853-19862. doi: 10.1039/C8TA08537D

Conflict of Interest: The authors declare that the research was conducted in the absence of any commercial or financial relationships that could be construed as a potential conflict of interest.

Copyright (C) 2020 Ashraf, Rizwan and Iqbal. This is an open-access article distributed under the terms of the Creative Commons Attribution License (CC BY). The use, distribution or reproduction in other forums is permitted, provided the original author(s) and the copyright owner(s) are credited and that the original publication in this journal is cited, in accordance with accepted academic practice. No use, distribution or reproduction is permitted which does not comply with these terms. 